\title{
Exciting perspectives for Translational Myology in the Abstracts of the 2018Spring PaduaMuscleDays: Giovanni Salviati Memorial - Chapter III - Abstracts of March 16, 2018
}

\author{
Ugo Carraro $(1,2,3)$
}

(1) Laboratory of Translational Myology, Department of Biomedical Sciences, University of Padova; (2) A\&C M-C Foundation for Translational Myology, Padova; (3) IRCCS Fondazione Ospedale San Camillo, Venezia-Lido, Italy

This article is distributed under the terms of the Creative Commons Attribution Noncommercial License (CC BY-NC 4.0) which permits any noncommercial use, distribution, and reproduction in any medium, provided the original author(s) and source are credited.

\begin{abstract}
Myologists working in Padua (Italy) were able to continue a half-century tradition of studies of skeletal muscles, that started with a research on fever, specifically if and how skeletal muscle contribute to it by burning bacterial toxin. Beside main publications in high-impact-factor journals by Padua myologists, I hope to convince readers (and myself) of the relevance of the editing Basic and Applied Myology (BAM), retitled from 2010 European Journal of Translational Myology (EJTM), of the institution of the Interdepartmental Research Center of Myology of the University of Padova (CIR-Myo), and of a long series of International Conferences organized in Euganei Hills and Padova, that is, the PaduaMuscleDays. The 2018Spring PaduaMuscleDays (2018SpPMD), were held in Euganei Hills and Padua (Italy), in March 14-17, and were dedicated to Giovanni Salviati. The main event of the "Giovanni Salviati Memorial", was held in the Aula Guariento, Accademia Galileiana di Scienze, Lettere ed Arti of Padua to honor a beloved friend and excellent scientist 20 years after his premature passing. Using the words of Prof. Nicola Rizzuto, we all share his believe that Giovanni "will be remembered not only for his talent and originality as a biochemist, but also for his unassuming and humanistic personality, a rare quality in highly successful people like Giovanni. The best way to remember such a person is to gather pupils and colleagues, who shared with him the same scientific interests and ask them to discuss recent advances in their own fields, just as Giovanni have liked to do". Since Giovanni's friends sent many abstracts still influenced by their previous collaboration with him, all the Sessions of the 2018SpPMD reflect both to the research aims of Giovanni Salviati and the traditional topics of the PaduaMuscleDays, that is, basics and applications of physical, molecular and cellular strategies to maintain or recover functions of skeletal muscles. The translational researches summarized in the 2018SpPMD Abstracts are at the appropriate high level to attract approval of Ethical Committees, the interest of International Granting Agencies and approval for publication in top quality, international journals. The abstracts of the March 16, 2018 Padua Muscle Day are listed in this chapter III. All 2018SpPMD Abstracts are indexed at the end of the Chapter IV.
\end{abstract}

Key Words: Giovanni Salviati, proof of concept, translational myology, PaduaMuscleDays Eur J Transl Myol 28 (1): 30-48, 2018 


\section{Abstracts of the 2018Spring PaduaMuscleDay, March 16, 2018}

\section{How the field of bioactive lipids was inspired by a discovery in the Salviati laboratory}

\section{Roger A. Sabbadini}

San Diego State University \& Stanford University, CA, USA

\section{E-mail: rsabbadini@mail.sdsu.edu}

Kay Words: Lipidomics, sphingolipids, antibody therapy, calcium channels, clinical trials

Biologically active lipids are now recognized as important mediators of critical physiologic and pathological processes, including cancer, inflammation, neurodegenerative diseases and dysfunctional fibrosis. We now know that many bioactive lipids like sphingosine-1-phosphate (S1P) and other sphingolipids as well as lysolipids such as lysophosphatidic acid (LPA) act as extracellular and intracellular mediators directly modulating ion channels, GPCRs and purinergic receptors in muscle, neurons, fibroblasts, vascular endothelia cells and transformed cells. In the Salviati laboratory in 1990, serendipity played a role in discovering the role of sphingolipids as calcium channel modulators in skeletal and cardiac muscle cells in skeletal muscle fatigue and contributing to negative ionotropic activity in the heart. ${ }^{85-88}$ The seminal finding in the Salviati lab led us on a 25-year journey, resulting in the creation of a biotechnology company, Lpath Inc, and the development of clinical drug candidates, including highly specific monoclonal antibodies (mAbs) against S1P and LPA (Figure 14). The humanized form of the
anti-S1P mAb, sonepcizumab, is a potential first-in-class therapeutic agent which functions as a "molecular sponge" to target and neutralize the bioactive lipid target. Sonepcizumab blocks the tumorigenic and angiogenic effects of dysregulated S1P produced by cancer cells and during pathological angiogenesis. ${ }^{89,90}$ These efficacy signals plus a strong safety profile in GLP toxicology studies supported an IND and the initiation of clinical trials. A Phase 1 safety trial demonstrated that systemic formulation of sonepcizumab, ASONEPTM, was welltolerated with no drug-related SAEs. A Phase 2 a trial was subsequently completed in renal cell carcinoma patients using ASONEPTM, while an ocular formulation of the same mAb, iSONEPTM, was used in recently completed clinical trials for the treatment wet AMD patients. The anti-LPA mAb, Lpathomab, was used in a successful Phase 1 clinical trial in healthy volunteers. An IND is open with the FDA to use this antibody in the treatment of neuropathic pain and a second IND is anticipated using Lpathomab in traumatic brain injury patients. None of these endeavors would have been possible without the inspiration of Giovanni Salviati and the excellent collaborators he assembled at the University of Padova. I will forever treasure Giovanni's friendship.

85. Sabbadini R, McNutt W, Jenkins G, Betto R, Salviati G. Sphingosine is endogenous to cardiac and skeletal muscle. Biochem Biophys Res Commun. 1993;193:752-8.

86. Betto R, Teresi A, Turcato F, Salviati G, Sabbadini RA, Krown K, Glembotski CC, Kindman LA, Dettbarn C, Pereon $Y, \quad$ Yasui $K, \quad$ Palade PT. Sphingosylphosphocholine modulates the ryanodine receptor/calcium-release channel of cardiac

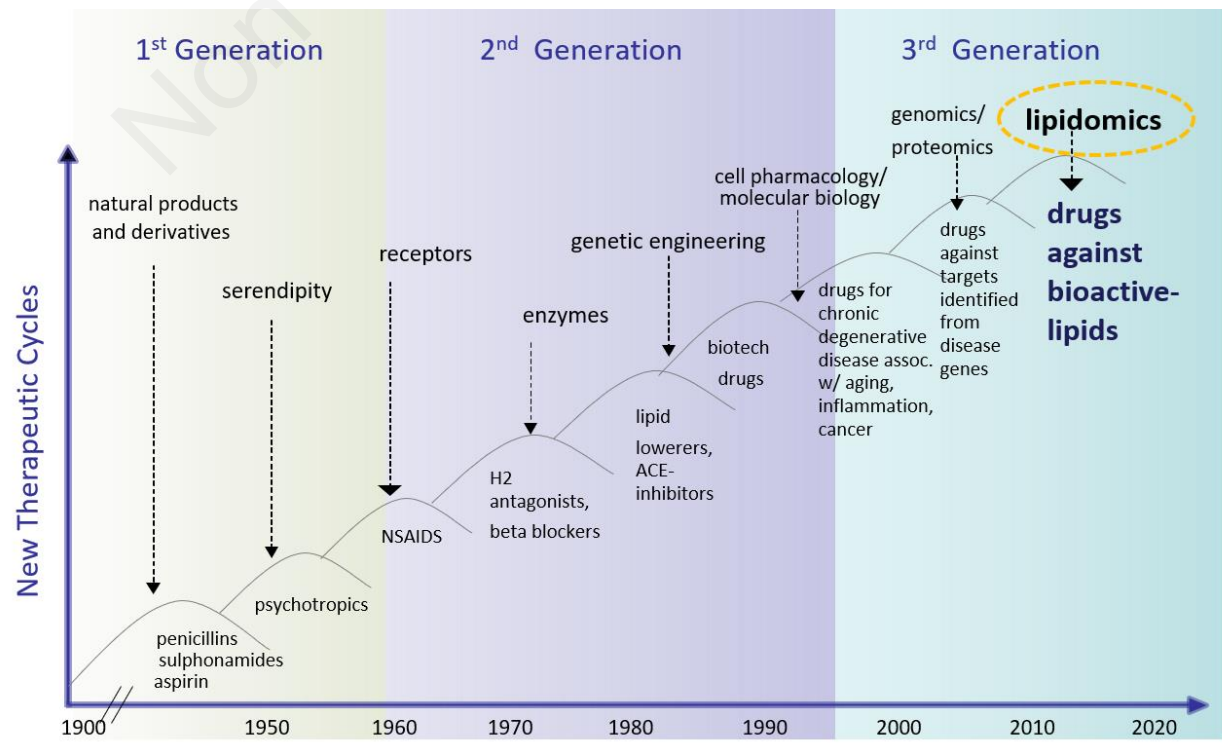

Fig 14. Lipidomics is a natural follow-on to genomics/proteomics. 
sarcoplasmic reticulum membranes. Biochem J 1997;322 ( Pt 1):327-33.

87. Dettbarn CA, Betto R, Salviati G, Palade P, Jenkins GM, Sabbadini RA. Modulation of cardiac sarcoplasmic reticulum ryanodine receptor by sphingosine. J Mol Cell Cardiol 1994;26:229-42.

88. Reynolds GM, Visentin B, Sabbadini $R$. Immunohistochemical Detection of Sphingosine-1Phosphate and Sphingosine Kinase-1 in Human Tissue Samples and Cell Lines. Methods Mol Biol 2018;1697:43-56. doi: 10.1007/7651_2017_44.

89. Tsuji S, Chen X, Hancock B, et al. Preclinical evaluation of VAX-IP, a novel bacterial minicell-based biopharmaceutical for nonmuscle invasive bladder cancer. Mol Ther Oncolytics 2016;3:16004. doi: 10.1038/mto.2016.4. eCollection 2016.

90. Bouquerel P, Gstalder C, Müller D, et al. Essential role for SphK1/S1P signaling to regulate hypoxia-inducible factor $2 \alpha$ expression and activity in cancer. Oncogenesis. 2016;5:e209. doi: 10.1038/oncsis.2016.13.

$* * * * *$

\section{Weak by machines: Skeletal muscles as a target in ICU Patients}

\section{Lars Larsson}

Department of Physiology \& Pharmacology, Department of Clinical Neuroscience, Clinical Neurophysiology, Karolinska Institutet, Stockholm, Sweden

\section{E-mail: lars.larsson@ki.se}

Key words: Myosin, skinned fiber, muscle paralysis

Intensive care and ICUs have undergone significant development during the past 65 years due to improvements in medical technology, progress in therapeutics, and improved understanding of pathophysiology and pathogenesis. Furthermore, evidence-based medicine has resulted in significant changes in the treatment of critically ill ICU patients, moving towards fewer and less invasive interventions and more humane care. In parallel with lowered mortalities, neuromuscular dysfunction induced by the ICU-treatment has become increasingly apparent. The most common and clinically important are the Critical Illness Myopathy (CIM) characterized by paralysis of all limb and trunk muscles and the Ventilator Induced Diaphragm Dysfunction (VIDD) resulting in delayed weaning from the ventilator due to impaired diaphragm function. Both CIM and VIDD are associated with enormous negative consequences for patient quality of life and health care costs. Today, critical care is one of the fastest growing hospital disciplines. Because of the growing need for critical care, ICUs have been predicted to occupy one third of hospital beds by 2020. Two decades ago, we diagnosed the first patient with CIM in Scandinavia (Figure 15). Today, we diagnose $\sim 1-2$ ICU patients per week with CIM at the Karolinska Hospital, Stockholm by combining electrophysiological measurements with quantification of myofibrillar protein expression in percutaneous muscle biopsies. CIM is today recognized as the most common cause underlying acquired muscle paralysis among ICU patients. ${ }^{91-94}$ In addition to the partial or complete paralysis of limb muscles, the major inspiratory muscle (the diaphragm) is severely affected by long-term mechanical ventilation, resulting in VIDD. There is a strong need for experimental animal models mimicking the ICU condition to permit analyses of the mechanisms underlying CIM and VIDD due to the heterogeneity among ICU patients, such as polypharmacy, underlying disease, clinical history, etc. ${ }^{95,96}$ During the past two decades, we have used a porcine and a rat experimental ICU model to improve our understanding of underlying mechanisms and evaluating different interventions strategies. In both CIM and VIDD, myosin is playing a

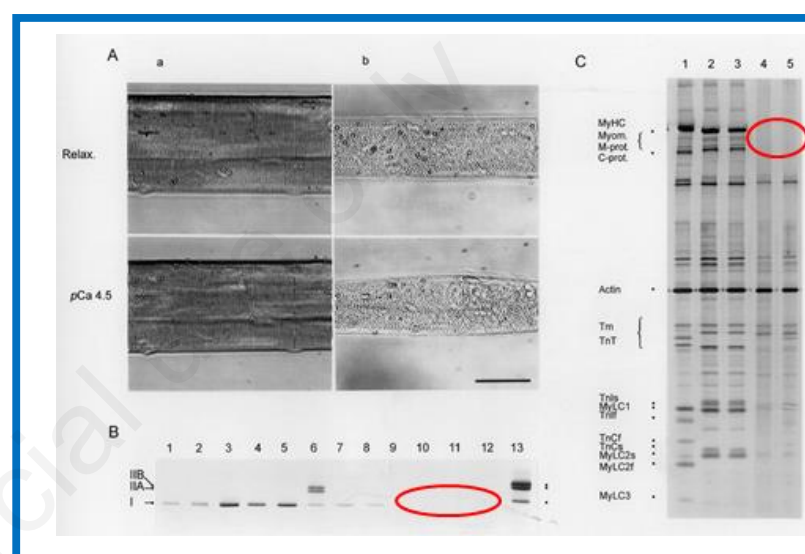

Fig 15. Myofibrillar protein isoform composition A. Chemically skinned single muscle cells from the tibialis anterior muscle from a normal control subject (a) and a patient with CIM (b) in relaxing solution (Relax.) andduring maximum activation ( $\mathrm{pCa}$ 4.5). Scale bar, $50 \mu \mathrm{m}$. B. Electrophoretic separation of MyHC isoforms by $6 \%$ SDS-PAGE. MyHCs were separated from single tibialanterior fiber segments (1-5, 7-10), bundles of 10 tibial anterior fibers $(11,12)$, and from single $10 \mu \mathrm{m}$ cross-section of a vastus lateralis muscle biopsy $(6,13)$ expressing three MyHCs bands (types I, IIA and IIB (=IIX)). Lanes 9-12 are from a quadriplegic patient (lane 10 corresponds to the fiber $b$ above, A) and the other lanes are from normal control subjects. C. Electrophoretic separation of thickand thin-filament protein isoforms with $12 \%$ SDS-PAGE. Fibers 1-3 are from the tibialis anterior muscle of a patient with hemi-paresis due to an upper motoneuron lesion. Lane 1 is from the paretic side and lanes 2-3 from the nonparetic normal side. Lanes 4 and 5 correspond to the fiber bundles from the quadriplegic patient, i.e. the same bundles as lanes 11 and 12 on the $6 \%$ SDS-PAGE (B)(2). 
pivotal role in the pathogenesis but the mechanisms are different in CIM and VIDD. Specific intervention strategies have been evaluated or are presently being tested with the goal of translating these interventions to the clinic.

91. Larsson L, Li X, Edström L, Eriksson LI, et al. Loss of muscle myosin and acute quadriplegia in patients treated with non-depolarizing neuromuscular blocking agents and corticosteroids. Underlying cellular and molecular mechanisms. Critical Care Medicine 2000;28:34-45.

92. Ochala J, Gustafson A-M, Li M, et al. Preferential skeletal muscle myosin loss in response to mechanical silencing in a novel rat intensive care unit model: underlying mechanisms. J Physiol (Lond) 2011;589:2007-26.

93. Renaud G, Llano-Diez M, Ravara B, et al. . Sparing of muscle mass and function by passive loading in an experimental intensive care unit model $J$ Physiol 2013;591(Pt 5):1385-402.

94. Llano-Diez M, Renaud G, Andersson M, et al. Passive mechanical loading improves muscle function but not mass in immobilized intensive care unit patients. Critical Care 2012;16:R209 doi:10.1186/cc11841

95. Corpeno R, Dworkin B, Bergman H-M, et al. Time-course analysis of mechanical ventilation-induced diaphragm contractile muscle dysfunction. J Physiol 2014:592:3859-80.

96. Salah H, Li M, Cacciani N, Gastaldello S,et al. The chaperone co-inducer BGP-15 alleviates ventilation induced diaphragm dysfunction Science Translational Medicine 2016;8(350):350ra103. doi: 10.1126/scitransl med.aaf7099.

$* * * * *$

Investigating muscular dystrophy in the lab of Giovanni Salviati

Romeo Betto
Neurosciences Institute, CNR Padova, Italy

\section{E-mail:romeo.betto@gmail.com}

Kaywords: Muscular dystrophy, $\alpha$-sarcoglycan, sarcoglycanopathy, ER protein maturation, ER-associated protein degradation pathway, pharmacological therapy

Since the seminal work of Luis Kunkle (1987) identifying dystrophin as responsible for Becker and Duchenne muscular dystrophy, ${ }^{97}$ large efforts were devoted to reveal the critical physiological function of the protein. Giovanni Salviati was soon involved in two important studies revealing that dystrophin is localized at the sarcolemma of muscle fibers. ${ }^{98,99}$ Later, he demonstrated that dystrophin is phosphorylated by endogenous protein kinases to regulate the interaction with actin. ${ }^{101,102}$ Then, his attention was devoted to the diverse components of the dystrophin-associated protein (DAP) complex (Fig. 16,A). Along these studies, it was discovered that one of the dystrophin-associated proteins, $\alpha$-sarcoglycan, is an ecto-ATPase, and its activity was then well characterized. ${ }^{103,104}$. The role of this extracellular enzymatic activity of $\alpha$-sarcoglycan, of sarcoglycan complex and, in the end of dystrophin complex, remains still undefined. Anyway, the relevance of sarcoglycans is evident by the fact that genetic defects of one of the four sarcoglycans has severe consequences on muscle function, causing limb-girdle muscular dystrophy (sarcoglycanopathy). The majority of sarcoglycanopathies are associated with missense mutations that generate substitution of single residues that could lead to a misfolded protein. Analysis of muscle samples from $\alpha$-sarcoglycan patients shows that these mutations result in the almost complete absence of the

\section{A}

B
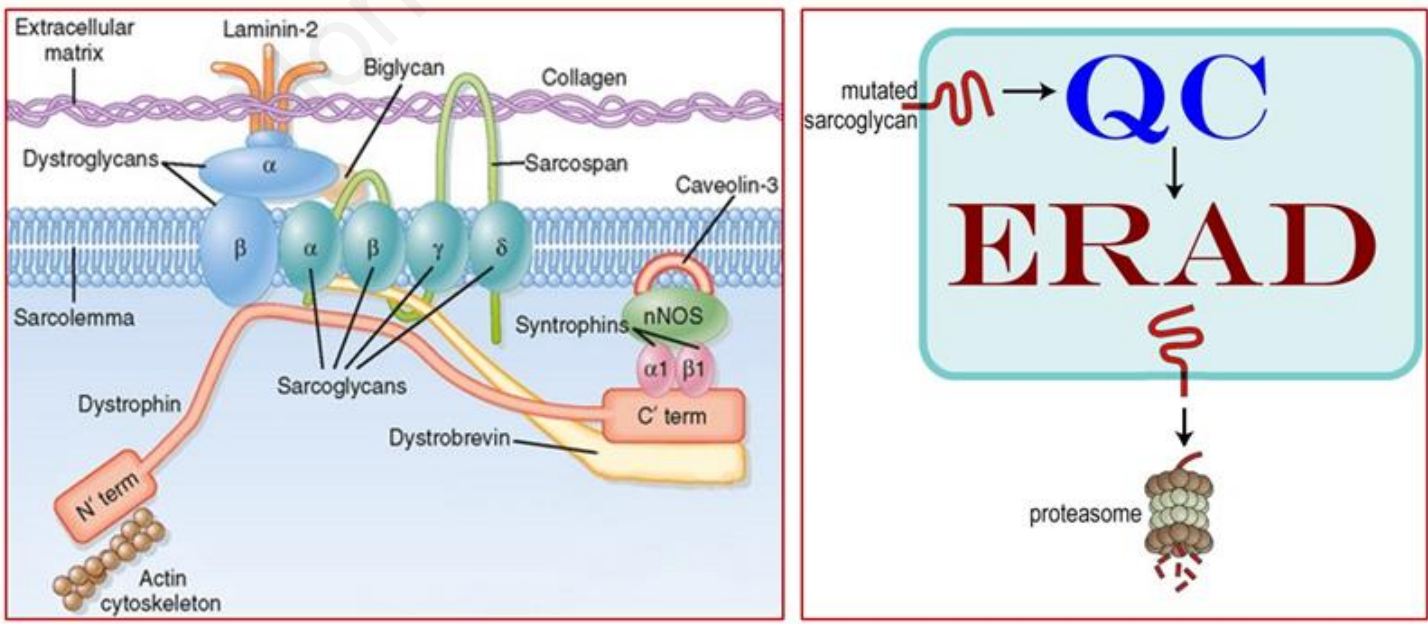

Fig 16. A, simplified scheme of dystrophin-associated proteins complex. B, degradation pathway of sarcoglycan mutant proteins. QC, quality control; ERAD, ER protein-associated degradation. 
protein from the cell membrane. Sarcoglycans are transmembrane proteins that mature in the endoplasmic reticulum, where they are severely scrutinized by an efficient quality control (QC) system. Therefore, misfolded proteins are identified and retrotranslocated to the cytosol for proteasomal degradation through the ERassociated protein degradation (ERAD) pathway (Fig. 16, B). Sequence analysis indicates that many $\alpha$ sarcoglycan missense mutations might not have functional consequences. Nevertheless, often the mutant protein is intercepted by the QC system and eliminated. ${ }^{105}$ Recently, we demonstrated that preventing proteasomal degradation increases the possibility of mutant sarcoglycan to overcome the QC system and move to the cell surface. ${ }^{106}$ Moreover, misfolded "functional" sarcoglycans could be rescued to the cell membrane by assisting them in the maturation process along the ER secretory pathway. ${ }^{105}$ Finally, we demonstrated the effectiveness of small molecules, already used with the cystic fibrosis protein, in rescuing $\alpha$-sarcoglycan mutant proteins and the entire sarcoglycan complex to the cell membrane. These results represent the premise for future pharmacological treatment of sarcoglycano-pathy, ${ }^{106}$ the final objective of the pioneering work initiated by Giovanni Salviati.

97. Hoffman EP, Brown RH Jr, Kunkel LM. Dystrophin: the protein product of the Duchenne muscular dystrophy locus. Cell 1987 Dec 24;51(6):919-28.

98. Bonilla E, Samitt CE, Miranda AF, et al. Duchenne muscular dystrophy: deficiency of dystrophin at the muscle cell surface. Cell 1988;54:447-52.

99. Salviati $G$, Betto $R$, Ceoldo $S$, et al. Cell fractionation studies indicate that dystrophin is a protein of surface membranes of skeletal muscle. Biochem J 1989;258:83741.

100. Luise M, Presotto C, Senter L, et al. Dystrophin is phosphorylated by endogenous protein kinases. Biochem J 1993;293:243-7.

101. Senter L, Ceoldo S, Petrusa MM, Salviati G. Phosphorylation of dystrophin: effects on actin binding. Biochem Biophys Res Commun 1995;206:57-63.

102. Betto R, Senter L, Ceoldo S, et al. Ecto-ATPase activity of alpha-sarcoglycan (adhalin). J Biol Chem 1999;274:7907-12.

103. Sandonà D, Betto R. Sarcoglycanopathies: molecular pathogenesis and therapeutic prospects. Expert Rev Mol Med 2009;11:e28.

104. Gastaldello S, D'Angelo S, Franzoso S, et al. Inhibition of proteasome activity promotes the correct localization of disease-causing $\alpha$-sarcoglycan mutants in HEK-293 cells constitutively expressing $\beta$-, $\gamma$-, and $\delta$-sarcoglycan. Am J Pathol 2008;173:170-81.

105. Bianchini E, Fanin M, Mamchaoui K, et al. Unveiling the degradative route of the V247M $\alpha$-sarcoglycan mutant responsible for LGMD-2D. Hum Mol Genet 2014;23:3746-58.

106. Carotti M, Marsolier J, Soardi M, et al. Repairing folding-defective $\alpha$-sarcoglycan mutants by CFTR correctors, a potential therapy for Limb Girdle Muscular Dystrophy 2D. Hum Mol Genet 2018, in press.
$* * * * *$

Mitochondrial Disorders: learning function from dysfunction. Perturbed redox signaling exacerbates the mitochondrial myopathy in a disease model by affecting mitochondrial biogenesis

Sukru Anil Dogan (a), Raffaele Cerutti (a), Gloria BreaCalvo (b), Howard T. Jacobs (3,4), Marten Szibor (c,d), Carlo Viscomi (a), Massimo Zeviani (a)

(a) MRC Mitochondrial Biology Unit, University of Cambridge, Wellcome Trust/MRC Building Hills Road, Cambridge, UK; (b) Centro Andaluz de Biología del Desarrollo and CIBERER, Instituto de Salud Carlos III, Universidad Pablo de Olavide-CSIC-JA, Sevilla, Spain; (c) Institute of Biotechnology, FI-00014 University of Helsinki, Finland; (d) BioMediTech and Tampere

University Hospital, University of Tampere, Finland.

E-mail: massimo.zeviani@mrc-mbu.cam.ac.uk

Key Words: Mitochondrial myopathy; reactive oxygen species; mitochondrial respiratory chain; alternative oxidase; cytochrome c oxidase; mouse model

Mutations in a vast array of genes encoded by either the nuclear or mitochondrial DNA (mtDNA) impair the activity of the respiratory chain and lead to primary mitochondrial diseases. Several interconnected mechanisms account for the cellular consequences of OXPHOS defects, including reduced ATP synthesis, increased production of reactive oxygen species (ROS), altered ion trafficking, or abnormalities in mitochondrialrelated execution pathways such as apoptosis and autophagy. In particular, ROS are by-products of normal respiration, but can increase when the respiratory chain is impaired. ROS are in fact deemed to play a "hormetic" double role: in physiological conditions, low levels of ROS act as signaling molecules regulating homeostatic pathways related to mitochondrial bioenergetics, whereas at high levels they act as toxic agents damaging cellular components, including nucleic acids, proteins and lipids (Figure 17). ${ }^{107}$ ROS are generated at different sites along the respiratory chain, with $\mathrm{CI}, \mathrm{CII}$ and CIII playing the main role. ${ }^{108}$ Alternative oxidases (AOX) are membranebound, single-protein mitochondrial enzymes evolved in plants and lower eukaryotes to maintain electron flow when the respiratory chain is inhibited. AOX acts by directly transferring electrons from $\mathrm{CoQ}$ to $\mathrm{O} 2$, thus bypassing CIII and CIV, and preventing over-reduction of the CoQ pool. Notably, AOX activity is not associated to proton pumping across the inner mitochondrial membrane and does not contribute directly to the 

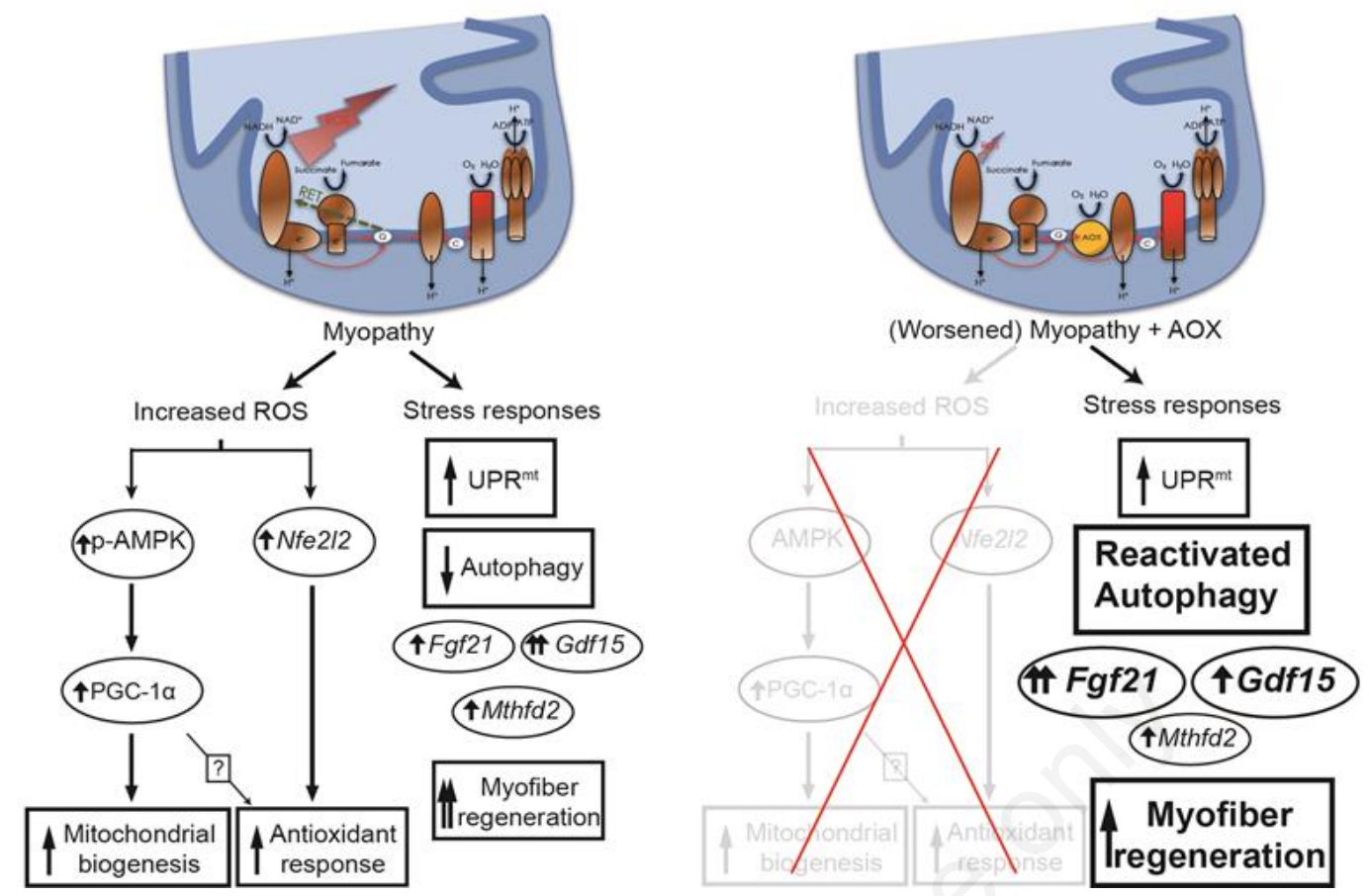

Fig 17. Schematic depiction of ROS related pathways in COX-defective mitochondrial myopathy, and the hypothesized effect of $A O X$.

formation of $\triangle \mathrm{P}$ and $\mathrm{ATP}$ synthesis. However, in the presence of CIII or CIV defects, the increase in proton pumping at $\mathrm{CI}$, due to the re-activation of the electron flow, may sustain the formation of the electrochemical gradient, and ATP production. The ability of AOX to limit excessive generation of ROS and maintain redox homeostasis has been exploited to improve the phenotype of cellular and fly models carrying CIII and CIV defects, ${ }^{109}$ whereas its use in mammalian models has not been explored so far. Here, we report the in vivo effects of AOX expressed in a muscle specific knockout (KO) mouse for Cox 15 (Cox15sm/sm), encoding the terminal enzyme of the biosynthetic pathway of heme a, an essential prosthetic group of CIV (cytochrome c oxidase [COX]). We tested the efficacy of AOX expression in a mammalian in vivo organism, by crossing Cox $15 \mathrm{sm} / \mathrm{sm}$ mice (KO), with an AOX transgenic mouse. Surprisingly, the double KO-AOX mutants had an exacerbated phenotype compared to naïve KO mice, characterized by decreased lifespan, body weight and spontaneous movements, and a staggering worsening of the myopathy, including decrease of COX activity and myofiber cross-sectional areaCitrate synthase activity, mtDNA copy number, and TFAM levels were also reduced in $\mathrm{KO}-\mathrm{AOX}$ vs. $\mathrm{KO}$ muscles, suggesting impaired mitochondrial biogenesis. Accordingly, PGC$1 \alpha$ and phosphorylated AMP levels were decreased in KO-AOX vs. KO mice. KO-AOX mice showed decreased ROS production, increased aconitase activity and decreased ROS detoxifying enzymes. We propose that reverse electron transfer at Complex I generates
ROS-dependent signals, which trigger a mitochondriogenic pathway that helps mitigate the biochemical, morphological and clinical signs of mitochondrial myopathy. Our findings warrant a critical reappraisal of the pathogenic mechanisms and therapeutic options of mitochondrial diseases.

107. Yun J, Finkel T. Mitohormesis. Cell Metab 2014;19:75766.

108. Brand M. Mitochondrial generation of superoxide and hydrogen peroxide as the source of mitochondrial redox signaling. In Free Radic Biol Med 2016, pp. 14-31.

109. El-Khoury R., Kemppainen K., Dufour, et al. Engineering the alternative oxidase gene to better understand and counteract mitochondrial defects: state of the art and perspectives. Br J Pharmacol 2014;171:2243-9.

$$
* * * * *
$$

\section{Mitochondria as therapeutic targets in muscle diseases}

\section{Paolo Bernardi} Department of Biomedical Sciences, University of
Padova, Italy

\section{E-mail:paolo.bernardi@unipd.it}

Key Words: mitochondria, calcium, permeability, muscle diseases

Mitochondrial dysfunction as a general mechanism for cell death in muscle diseases has been proposed more than 40 years ago. ${ }^{110}$ The key events of the proposed pathogenetic sequence (cytosolic $\mathrm{Ca} 2+$ overload, excess 
mitochondrial $\mathrm{Ca} 2+$ uptake, functional and then structural damage of mitochondria, energy shortage, worsened elevation of cytosolic $\mathrm{Ca} 2+$ levels, hypercontracture, fiber necrosis) (Figure 18) have been confirmed in detail by subsequent work in a variety of models. The implication of the hypothesis was that it may provide the basis for a more rational treatment for some conditions even before their primary causes are known. ${ }^{110}$ This prediction is being fulfilled, and the full potential of mitochondria as drug targets in muscle diseases may become a reality, particularly through inhibition of the mitochondrial permeability transition pore (PTP) and its regulator cyclophilin D. ${ }^{111}$ The PTP is a high-conductance channel whose opening requires matrix $\mathrm{Ca} 2+$ and additional factors including oxidative stress. While short openings may be involved in $\mathrm{Ca} 2+$ homeostasis, providing a $\mathrm{Ca} 2+$ release pathway preventing matrix $\mathrm{Ca} 2+$ overload, long openings may cause matrix swelling and cytochrome $\mathrm{c}$ release leading to cell demise. ${ }^{111}$ Convincing data are available to support the idea that PTP opening is a causal event in muscle diseases including collagen VI myopathies, ${ }^{112}$ and dystrophin-related disease models. ${ }^{13-115}$ PTP inhibitors thus represent promising therapeutic agents for these and possibly other human muscle diseases. I will illustrate how our work (which merged mitochondrial pathophysiology and muscle function) developed over the years; and how Giovanni Salviati encouraged me and supported the earlier stages of my career.

110. Wrogemann K, Pena SD. Mitochondrial calcium overload: A general mechanism for cell-necrosis in muscle diseases. Lancet 1976;1:672-4.
111. Zulian A, Schiavone M, Giorgio V, Bernardi P. Forty years later: Mitochondria as therapeutic targets in muscle diseases. Pharmacol Res 2016;113:563-73.

112. Tiepolo T, Angelin A, Palma E, et al. The cyclophilin inhibitor Debio 025 normalizes mitochondrial function, muscle apoptosis and ultrastructural defects in Col6al -/myopathic mice. Br J Pharmacol 2009;157:1045-52.

113. Millay DP, Sargent MA, Osinska H, et al. Genetic and pharmacologic inhibition of mitochondrial-dependent necrosis attenuates muscular dystrophy. Nat Med 2008; 14:442-7.

114. Schiavone M, Zulian A, Menazza S, et al. Alisporivir rescues defective mitochondrial respiration in Duchenne muscular dystrophy. Pharmacol Res 2017;125:122-31.

115. Wissing ER, Millay DP, Vuagniaux G, Molkentin JD. Debio-025 is more effective than prednisone in reducing muscular pathology in mdx mice. Neuromuscul Disord 2010;20:753-60.

$* * * * *$

\section{Coenzime Q deficiency and skeletal muscle}

\section{Leonardo Salviati}

University of Padova, Italy

E-mail: leonardo.salviati@unipd.it

Key Words: Coenzime $Q$, Coenzime $Q$ deficiency, $C O Q$ genes, bypass therapy

Coenzyme Q $(\mathrm{CoQ})$ is a small lipid which plays a crucial role in cellular metabolism. It is comprised of a quinone group and of a polyisoprenoid tail of different length in different species: 6 units in yeast, 8 in C. elegans, 9 and 10 units in mice, and 10 units in humans (CoQ10). CoQ has multiple functions: it is an electron carrier in the mitochondrial respiratory chain (it shuttles electrons

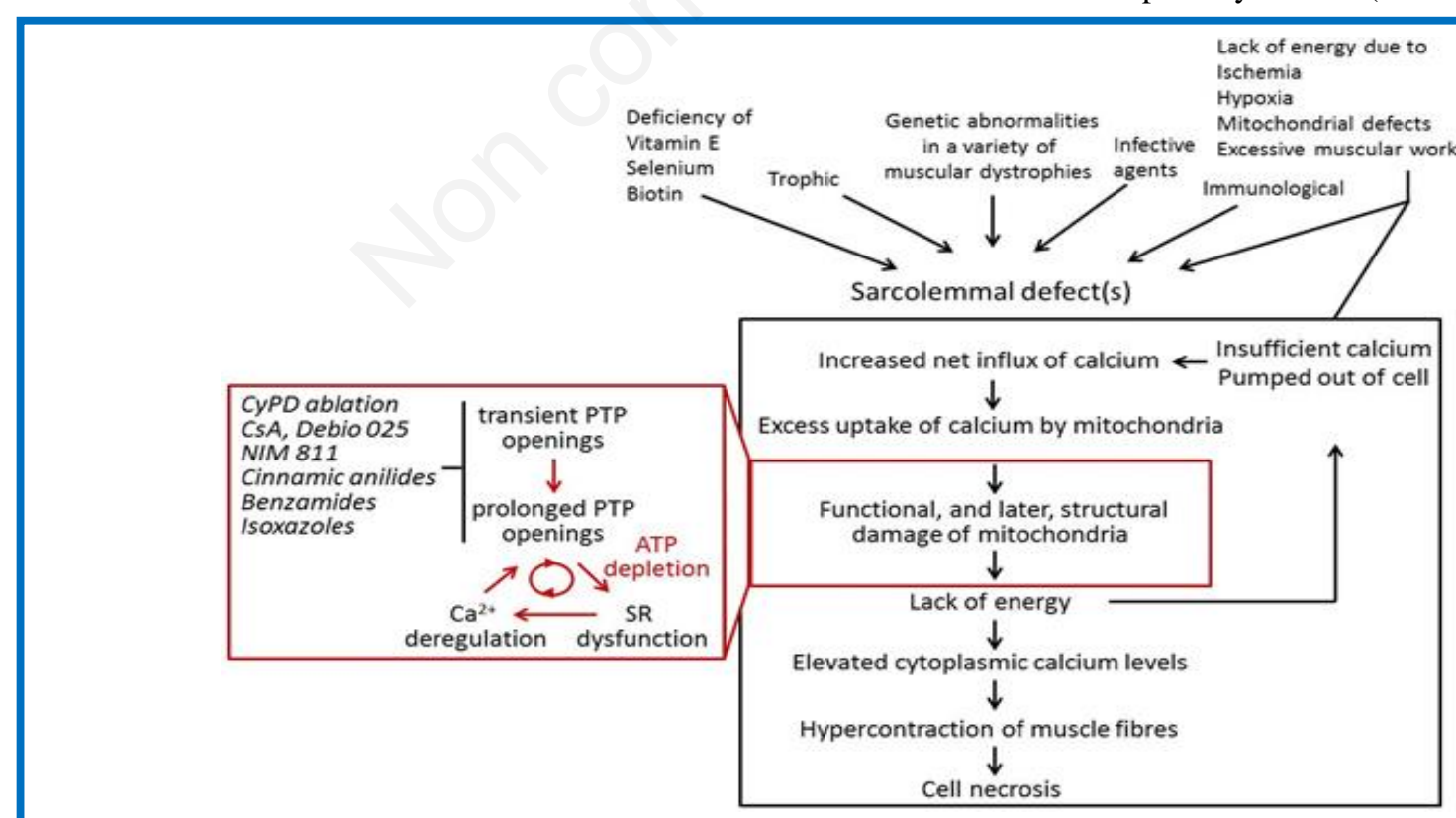

Fig 18. $\mathrm{Ca}^{2+}$-dependent involvement of mitochondria in muscle cell death. The scheme is taken from Wrogemann $K$ (1976), ${ }^{1}$ as modified in Zulian A (2016). ${ }^{2}$ 
from complexes I and II to complex III), it is a cofactor of several other mitochondrial dehydrogenases (such as ETFDH, involved in beta oxidation, and DHODH required for pyrimidine biosynthesis) and of uncoupling proteins, it is a major antioxidant, and it is a modulator of the permeability transition pore. CoQ is produced by a complex (and not yet completely understood) series of reactions which occur in the cytosol and within mitochondria. The quinone group is synthesized starting from tyrosine, while the isoprenoid tail share its initial steps with cholesterol biosynthesis. The terminal reactions occur within mitochondria and involve a set of enzymes organized into a multiprotein complex, which catalyze the modifications of the quinone group. At least 15 different proteins are involved in the biosynthetic pathway. Mutations in 9 of them have been associated to primary CoQ deficiency, a clinically and genetically heterogeneous group of disorders. A peculiar manifestation of CoQ deficiency is renal glomerular involvement manifesting as steroid-resistant nephrotic syndrome (SRNS). SRNS is rarely observed in mitochondrial disorders (only MELAS patients occasionally display this feature) which are usually associated with tubular dysfunction. Clinical phenotypes associated with CoQ deficiency range from fatal neonatal multiorgan failure to adult-onset encephalopathy. Specific genetic defects can be classified into three broad groups: those associated with SRNS (PDSS1, PDSS2, COQ2, COQ6, and COQ8B), those associated with encephalomyopathy but not with SRNS (COQ4, COQ7, and COQ9) and those associated with cerebellar ataxia (COQ8A). ${ }^{116}$ CoQ deficiency can also be secondary to defects in genes unrelated to CoQ biosynthesis such as other respiratory chain defects, APTX, BRAF, and ETFDH among the most common, and also to nongenetic causes. There are no patients with genetically primary deficiency presenting with isolated myopathy. Nevertheless muscle involvement is usual. ${ }^{107,108}$ Muscle biopsies display unspecific morphological features. Lipid accumulation on oil-red-O staining is evident in most patients; some display increased subsarcolemmal SDH staining, but Ragged -Red Fibers are usually absent. Conversely, a reduction of the combined activities of complexes I+III and II+III with normal activities of the isolated complexes is pathognomonic of CoQ deficiency. The diagnosis can be confirmed by direct measurements of $\mathrm{CoQ}$ content in muscle (even though a distinction between primary and secondary forms can be achieved only by genetic testing). Indeed, most patients with reduced Coenzyme Q in muscle have a secondary defect. In these cases the clinical and morphological features depend on the underlying defect. Both types of patients benefit from high dose, oral CoQ supplementation (in fact, primary CoQ deficiency is one of the few treatable mitochondrial disorders). Unfortunately, CoQ has a low bioavailability and not all patients respond to treatment. Recently, novel therapeutic approaches have been proposed based on analogues of the precursor of the quinone ring, which can bypass specific defect such as COQ6 and COQ7, and have a general stimulatory effect on the expression of COQ proteins. We have data showing how these treatments are superior to classical CoQ supplementation. ${ }^{117}$

116. Vazquez Fonseca L, Doimo M, Calderan C, et al. Mutations in COQ8B (ADCK4) found in patients with steroid-resistant nephrotic syndrome alter COQ8B function. Hum Mutat 2018;39:406-414. doi: 10.1002/humu.23376. Epub 2017 Dec 18.

117. Salviati L, Trevisson E, Doimo M, Navas P. Primary Coenzyme Q10 Deficiency. Editors. In: Adam MP, Ardinger HH, Pagon RA, Wallace SE, Bean LJH, Stephens K, Amemiya A, editors. Source, GeneReviews ${ }^{\circledR}$ [Internet]. Seattle (WA): University of Washington, Seattle; 1993-2018. 2017 Jan 26.

\section{$* * * * *$ \\ Single muscle fiber analyses: from myosin composition to metabolic profile \\ Stefano Schiaffino}

Venetian Institute of Molecular Medicine, Padova, Italy

\section{E-mail: stefano.schiaffino@unipd.it}

KeyWords: muscle fiber types, single muscle fiber proteomics, aging skeletal muscle

All tissues and organs are heterogeneous in terms of cell composition, due to the presence of tissue-specific cells, such as muscle fibers in skeletal muscle or hepatocytes in liver, and a variety of other cell types present in all tissues, such as fibroblasts and endothelial cells. A further layer of cellular heterogeneity is due to the existence of differences among the tissue-specific cells themselves. Skeletal muscles contain different types of muscle fibers, which are variously distributed in body muscles, and liver contains different types of hepatocytes, those located in centrolobular areas differing from those present in peripheral regions close to the portal triads. The differences between individual cells are masked in bulk analyses of tissue homogenates, which are commonly used for biochemical and molecular biology analyses, including epigenome, transcriptome and proteome analyses, thus current studies can only provide a rough, average view of the structural and metabolic profiles of the cells present in each tissue (Figure 19). Recent developments in single cell analysis, based on high-throughput methods for fluorescenceactivated cell sorting and microfluidics combined with powerful next generation sequencing approaches, allow to isolate single cells and define their epigenome and transcriptome profile. However, single cell proteomics is not yet possible, with the exception of skeletal muscle. The technique for single muscle fiber isolation after chemical skinning was introduced to Padova by Giovanni Salviati, who used this approach to identify three myosin heavy chain (MYH) bands in human skeletal muscle 
(Biral et al, 1988), ${ }^{118}$ and analyzed the effect of aging on the human MYH profile in collaboration with the group of Bengt Saltin (Klitgaard et al, 1990). ${ }^{119}$ Roberto Bottinelli and Carlo Reggiani used skinned muscle fibers to correlate the MYH isoform composition with the shortening velocity of the four fiber types present in rat skeletal muscle, using specific monoclonal anti-MYH antibodies developed in Padova for fiber typing (Bottinelli et al, 1991). ${ }^{120}$ Cytosolic soluble proteins are lost by chemical skinning, thus single muscle fibers manually dissected from freshly isolated muscles are required to resolve the metabolic profile of fiber types. Marta Murgia, working in the laboratory of Matthias Mann in Muenchen, has taken advantage of a highly sensitive proteomics workflow developed in Mann's lab to obtain the proteome of single muscle fibers. Using this approach, the mitochondrial proteome of mouse slow type 1 fibers was found to differ from that of mitochondria-rich fast $2 \mathrm{~A}$ and $2 \mathrm{X}$ fibers, thus validating the notion of mitochondrial specialization in different types of skeletal muscle fibers (Murgia et al, 2015; Schiaffino et al, 2015). ${ }^{121,122}$ The single-fiber proteomic approach has recently been used to investigate human muscle aging (Murgia et al, 2017). ${ }^{123}$ A striking result of this study has been the demonstration that glycolysis and glycogen metabolism are downregulated in fast but upregulated in slow muscle fibers with aging.

118. Biral D, Betto R, Danieli-Betto D, Salviati G. Myosin heavy chain composition of single fibres from normal human muscle. Biochem J 1988;250:307-8.

119. Klitgaard H, Zhou M, Schiaffino S, et al. Ageing alters the myosin heavy chain composition of single fibres from human skeletal muscle. Acta Physiol Scand. 1990;140:55-62.

120. Bottinelli R, Schiaffino S, Reggiani C. Force-velocity relations and myosin heavy chain isoform compositions of skinned fibres from rat skeletal muscle. J Physiol 1991;437:655-72.

121. Murgia M, Nagaraj N, Deshmukh AS, et al. Single muscle fiber proteomics reveals unexpected mitochondrial specialization. EMBO Rep 2015;16:387-95.

122. Schiaffino S, Reggiani C, Kostrominova TY, et al. Mitochondrial specialization revealed by single muscle fiber proteomics: focus on the Krebs cycle. Scand J Med Sci Sports. 2015;25(Suppl 4):41-8.

123. Murgia M, Toniolo L, Nagaraj N, et al. Single muscle fiber proteomics reveals fiber-type-specific features of human muscle aging. Cell Rep 2017;19:2396-409.

$$
* * * * *
$$

Hippo signalling and its role in skeletal muscle
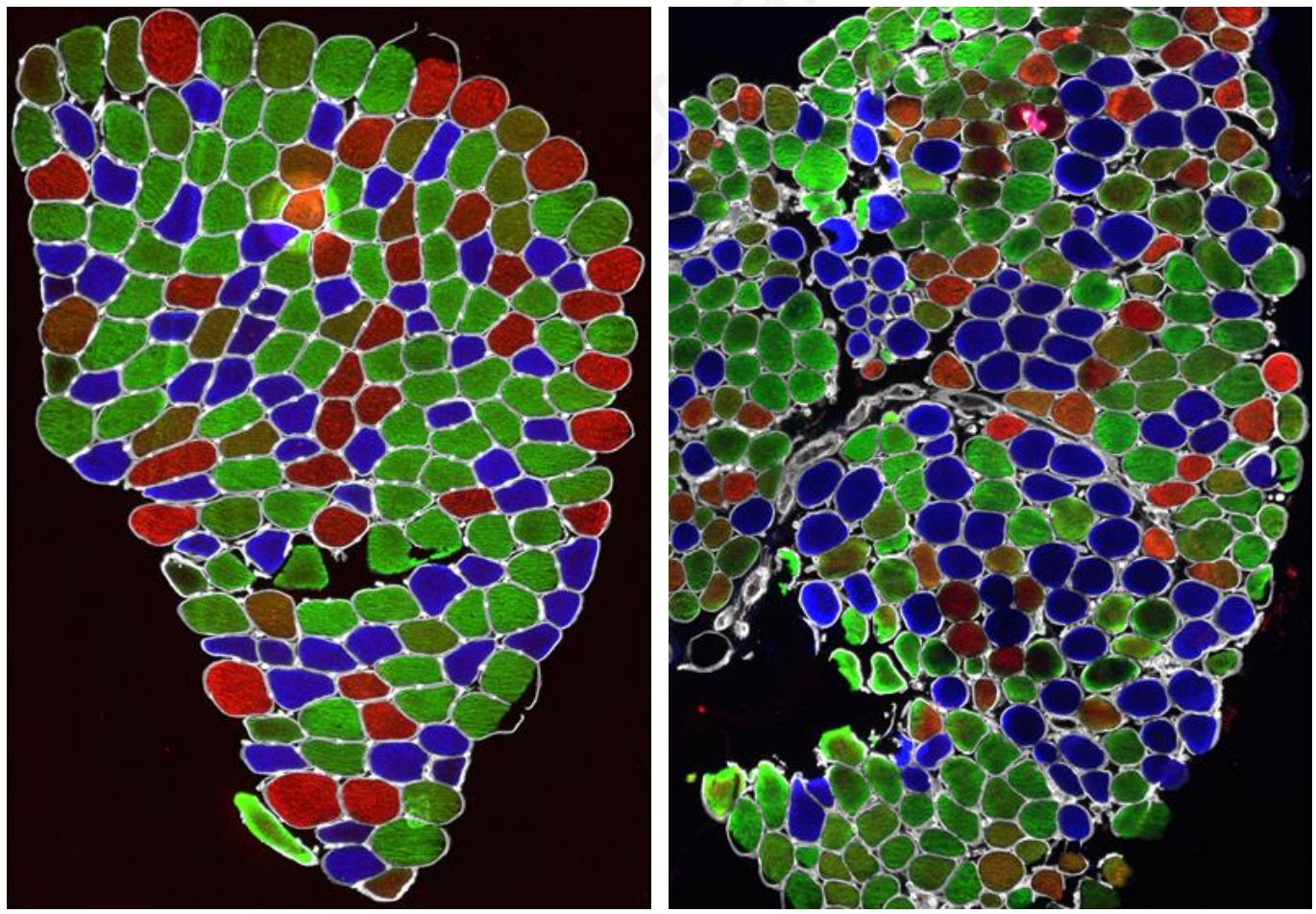

Fig 19. Sections of muscle biopsies from young (left) and elderly (right) individuals stained to reveal the presence of different myosin heavy chains with specific monoclonal antibodies. Three fiber types can be identified: slow/typel (anti-MYH7, blue), fast 2A (anti-MYH2, green), and fast $2 X$ fibers (anti-MYH1, red). These samples are part of a study involving biopsies from eight donors representing two age groups, younger (22-27) and older (65-75), which were used for single muscle fiber proteomics (see Murgia et al, Cell Rep 2017). ${ }^{114}$ 


\section{SpPMD: Giovanni Salviati Memorial, March 15-17}

Eur J Transl Myol 28 (1): 30-48, 2018

\section{Henning Wackerhage}

\section{Technical University of Munich, German}

Email: henning.wackerhage@tum.de

Keywords: Hippo, Yap, embryonal rhabdomyosarcoma, satellite cell,s muscle fibres, hypertrophy

The Hippo signal transduction network was discovered through several strands of research (Figure 20,A): 1) Hippo pathway: Screening for tumour suppressors in the fly led to the discovery of the Hippo pathway genes that include two kinases, termed Mst1/2 and Lats $1 / 2$ in mammals. 2) Hippo transcriptional regulators: Research into transcriptional regulation in muscle and elsewhere led to the discovery of the transcriptional co-factors Yap (gene Yap1) and Taz (gene Wwtr1) that activate Tead14 transcription factors. 3) Link between Hippo pathway and transcription: The Hippo pathway inhibits Yap/TazTead1-4-dependent gene expression through phosphorylation of serine residues on Yap and Taz. 4) Hippo cross-talk: That the Hippo pathway is only one of many signaling modules that regulate Yap/Taz-Tead1-4dependent gene expression. Other Yap/Taz-Teadregulating signalling modules include Ampk, hypoxia, G-protein coupled receptors, mechanotransduction, and
Wnt signaling. Genes that encode Hippo signal transduction pathway members as well as Yap, Taz, and Tead1-4 are all expressed in skeletal muscle (Figure 20, B). Yap is active in myoblasts and activated satellite cells where it promotes proliferation but inhibits differentiation (Judson et al., 2012). ${ }^{124}$ Persistent Yap hyperactivity in activated satellite cells is sufficient to cause embryonal rhabdomyosarcomas (ERMS) in mice (Tremblay et al., 2014) ${ }^{125}$ and YAP is abundant and often nuclear in human ERMS. In muscle fibres, inducing the MCK promoter-driven expression of constitutively active YAP1 S127A in adult muscle fibres causes myopathy (Judson et al., 2013). ${ }^{126}$ In contrast, two other groups have shown that YAP expression in muscle fibres through other methods causes muscle fibre hypertrophy that is independent of mTOR. More recently, we have explored the regulation and function of the Vgll1-4 protein in muscle as they can bind Tead1-4 at the same site where Yap binds. We also identified Yap and Taz binding partners in myoblasts and myotubes and have compared the gene targets of Yap and Taz.

124. Judson RN, Tremblay AM, Knopp, P, et al. The Hippo pathway member Yap plays a key role in influencing fate decisions in muscle satellite cells. $J$ cell sci 2012:125:6009-19.

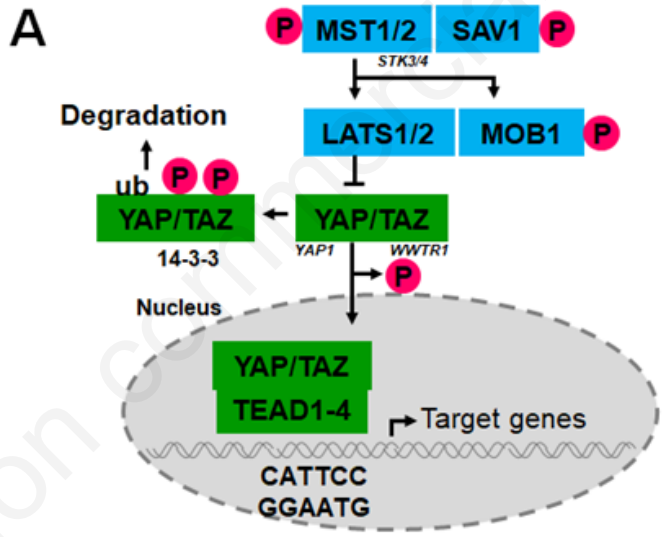

B Hippo in myoblasts

Hippo in muscle fibres

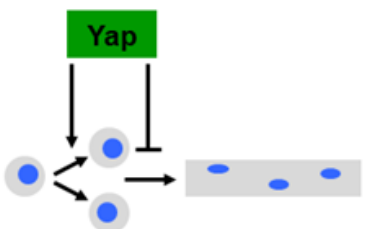

Proliferation but inhibits differentiation and is sufficient to cause ERMS
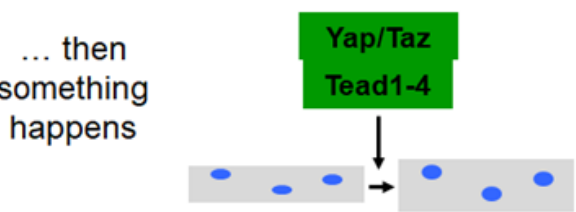

Physiological Yap/Taz-Tead1-4个 $\rightarrow$ hypertrophy?

Fig 20. Schematic depiction of the Hippo signal transduction network. A The Hippo kinases MST1/2 and LATS1/2 (SAV1 and MOB1 are auxiliary proteins) regulate YAP/TAZ through serine phosphorylation. Unphosphorylated YAP/TAZ is typically nuclear and activates TEAD1-4 transcription factors. B In myoblasts (activated satellite cells) YAP drives proliferation but inhibits proliferation. Persistent YAP hyperactivityis sufficient to cause ERMS. In differentiated muscle fibres physiological Yap activity causes hypertrophy but pathological Yap hyperactivity can cause atrophy and myopathy. 
125. Tremblay AM, Missiaglia E, Galli GG, et al. The Hippo transducer YAP1 transforms activated satellite cells and is a potent effector of embryonal rhabdomyosarcoma formation. Cancer cell 2014;26,273-87 87. doi: 10.1016/j.ccr.2014.05.029. Epub 2014 Jul 31.

126. Judson RN, Gray SR, Walker C, et al. Constitutive expression of Yes-associated protein (Yap) in adult skeletal muscle fibres induces muscle atrophy and myopathy. PloS one 2013;8:e59622.

$$
* * * * *
$$

\section{Caffeine-induced calcium release in human single muscle fibers}

Carlo Reggiani, Luana Toniolo

\section{Department of Biomedical Sciences, University of Padova, Italy}

\section{E-mail: carlo.reggiani@unipd.it}

Key Words: skeletal muscle fibers, sarcoplasmic reticulum, calcium release, caffeine

Caffeine is a well known activator of calcium release from sarcoplasmic reticulum (SR) via a specific interaction with the calcium channel ryanodine receptor (RyR). The recent discovery of the RyR atomic structure has shown that caffeine binds to a site encompassing the S2-S3 linker and CTD, contacting residues RyR1-
Trp4716 and RyR1- Ile4996, respectively (des Georges et al., 2016). ${ }^{127}$ At variance of ryanodine which locks RyR in an open state and removes the physiological regulation by $\mathrm{Ca} 2+, \mathrm{Mg} 2+$ and $\mathrm{ATP}$, caffeine increases the channel open probability without significantly affecting single-channel conductance (Rousseau et al., 1988) ${ }^{128}$ and without loosing the sensitivity to regulation by $\mathrm{Ca}^{2+}, \mathrm{Mg}^{2+}$ and ATP. In 1988 Salviati and Volpe proposed to adopt caffeine as a tool to study calcium release from SR of single rabbit fibers to investigate the diversity among slow and fast fibers. ${ }^{129}$ In a permeabilized fiber, the administration of suitable dose of caffeine triggers calcium release which is followed by a transient increase, or a wave, of free calcium concentration in the cytosol (Figure 21). The release of calcium is measured by tension development, thus using troponin $\mathrm{C}$ and myofibrillar proteins as calcium sensor. The protocol was then modified by Lamb and coworkers $(2001)^{130}$ who studied calcium release induced by caffeine in rat single muscle fibers after mechanical skinning, i.e. mechanical removal of the sarcolemma leaving SR intact. A compartmental model was designed to reconstruct the release of calcium taking into account diffusion and buffering in the cytosol and re-uptake to SR (Makabe et al 1996, Uttenweiler et al 1998). ${ }^{131,132}$ In our lab a modification of the method was first applied in

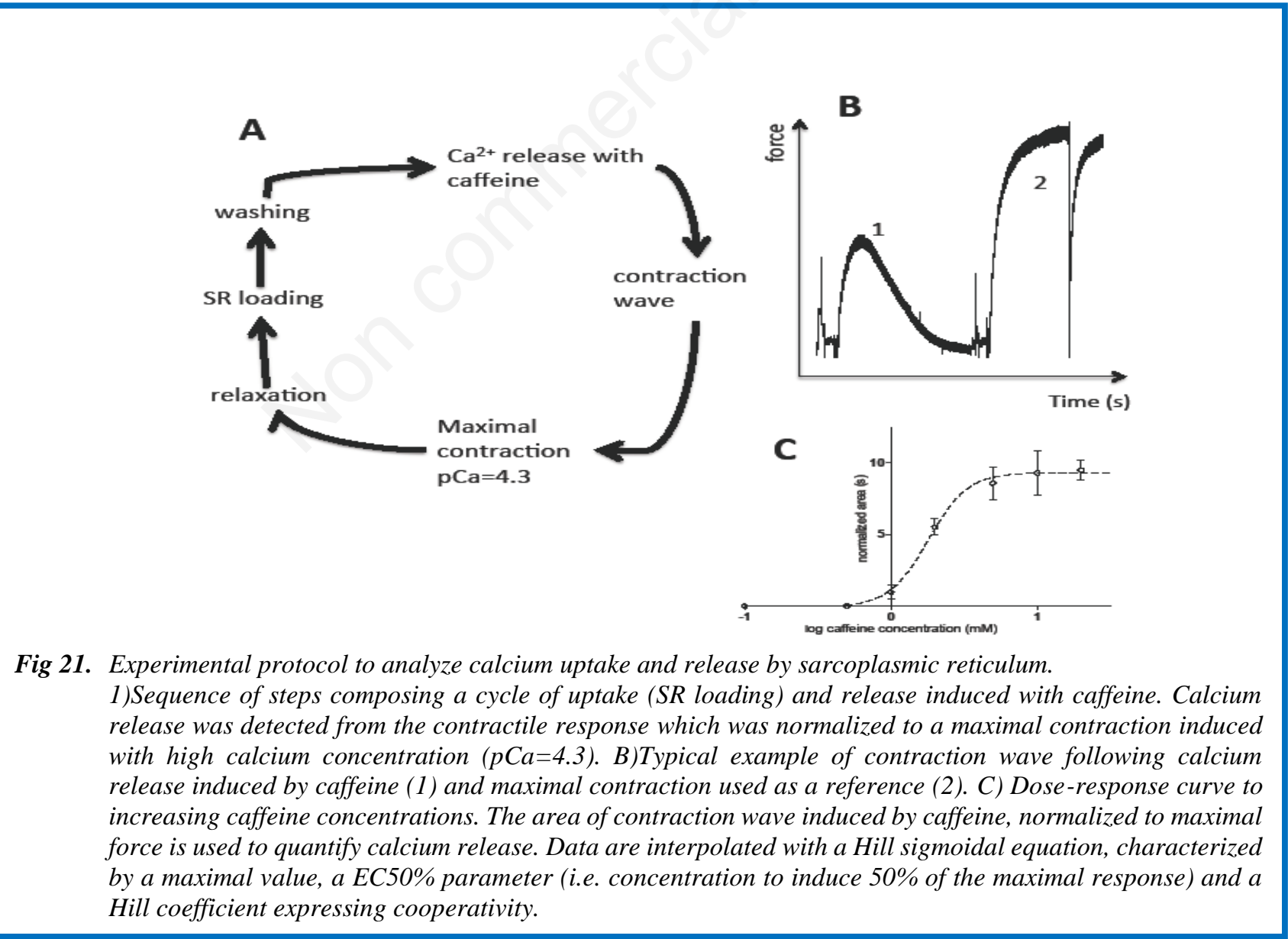


murine single muscle fibers to investigate the impact of RyR3 genetic ablation (Rossi 2001). ${ }^{133}$ Saponin was introduced as a tool to permeabilize sarcolemma preserving the integrity of SR membrane and thus its ability to take up, store and release calcium. The amount of calcium release was monitored from tension generation after caffeine administration, and was quantified either by measuring the rate of tension development or the area under the tension curve. A sygmoidal dose-response curve was obtained and the EC50\% values were in the range $0.1-1 \mathrm{mM}$ caffeine. The amplitude of the response was expressed with reference to tension developed during a maximal activation $(\mathrm{pCa}=4.6)$ in the same conditions of sarcomere length and temperature. More recently we started to apply that protocol with some slight modifications to single fibers from human biopsy samples. Under the conditions of 5 $\mathrm{mM}$ ATP, $1 \mathrm{mM} \mathrm{Mg}^{2+}$ and $\mathrm{pCa}=7$ in the perfusing medium and with the SR fully replenished after a long incubation $(5 \mathrm{~min})$ in the presence of $5 \mathrm{mM}$ ATP and $\mathrm{pCa}=6.6$, the $\mathrm{EC} 50 \%$ was about $1-2 \mathrm{mM}$ caffeine. There was a difference, as expected according to previous work (Lamb et al 2001) ${ }^{5}$, between slow and fast fibers, with slow fibers being more responsive (EC50\% $\approx 1.5 \mathrm{mM}$ ) than fast fibers $(\mathrm{EC} 50 \% \approx 2.5 \mathrm{mM})$. The method was applied to muscle fibers from patients carrying various mutations of the intraluminal calcium buffer calsequestrin (Rossi et al 2014, Barone et al 2016) ${ }^{134,135}$ and proved to be able to discriminate not only between wild type and mutated fibers but also between different mutations.

127. des Georges A., Clarke O.B., Zalk R., et al. Structural basis for gating and activation of RyRl. Cell 2016;167:145-57.

128. Rousseau E, Ladine J, Liu QY, Meissner G. Activation of the Ca2+ release channel of skeletal muscle sarcoplasmic reticulum by caffeine and related compounds. Arch. Biochem. Biophys 1988.267:75-86.

129. Salviati $G$, Volpe $P$. Ca2+ release from sarcoplasmic reticulum of skinned fast-and slowtwitch muscle fibers. Am J Physiol 1988:254:C459465

130. Lamb GD, Cellini MA, Stephenson DG. Different $\mathrm{Ca} 2+$ releasing action of caffeine and depolarisation in skeletal muscle fibres of the rat. $J$ Physiol 2001;531:715-28.

131. Makabe M, Werner O, Fink RH. The contribution of the sarcoplasmic reticulum Ca2+-transport ATPase to caffeine-induced $\mathrm{Ca2}+$ transients of murine skinned skeletal muscle fibres. Pflugers Arch 1996;432:717-26.

132. Uttenweiler D, Weber C, Fink RH. Mathematical modeling and fluorescence imaging to study the Ca2+ turnover in skinned muscle fibers. Biophys $J$ 1998;74:1640-53
133. Rossi R, Bottinelli $R$, Sorrentino $V$, Reggiani $C$. Response to caffeine and ryanodine receptor isoforms in mouse skeletal muscles. Am J Physiol Cell Physiol 2001;281:C585-94.

134. Rossi D, Vezzani B, Galli L, et al. A Mutation in the CASQ1 Gene Causes a Vacuolar Myopathy with Accumulation of Sarcoplasmic Reticulum Protein Aggregates. Hum Mutat 2014;35:1163-70.

135. Barone V, Del Re V, Gamberucci A, et al. Identification and characterization of three novel mutations in the CASQ1 gene in four patients with tubular aggregate myopathy. Hum Mutat 2017;38:1761-73.

$$
* * * * *
$$

\section{Lesson from ultrastructure: what images tell if you look closely}

Simona Boncompagni, Chieti University, Italy

Clara Franzini-Armstrong, University of Pennsylvania, Philadelphia, USA

\section{E-mail: simona.boncompagni@unich.it}

Keywords: Electron Microscopy, striated muscles, ultrastructure.

Standard electron microscopy (EM) provides the structural basis at the nanoscale level for unraveling cell functions and defining the basis for pathological alterations. For a period of time electron microscopy went out of fashion and often it has been considered simply too descriptive to be worthy of publication. However, the increased frequency of electron micrographs that accompany most recent publications involving normal and pathological cell biology are an indication that a need for such ultrastructural level substantiation of results has made a comeback. Unfortunately, very little attention is often paid to the quality of the material presented, mostly because data collection has been trusted to quickly and often facility employees who may not have sufficient knowledge on the tissue of interest. Striated muscles are specifically prone to misinterpretations due to alterations produced by incorrect preservation procedures and or poorly selected areas of interest. Empty fascination for numbers, lack of adequate background knowledge and the unfortunate rush to print have often resulted in the publication of faulty and/or useless data. Using examples from our extensive archive of micrographs and from published data we illustrate on the one hand how poor technique results in incomplete and/or faulty data and on the other hand how well done electron micrographs are extensive sources of information. From a well performed EM analysis and pictures we can deduce a lot. Indeed just to quote an old instance: the mechanisms of muscle contraction (A. Huxley), of excitation-contraction coupling and of calcium homeostasis could not have been elucidated without the structural foundation revealed by EM. $^{136}$ More recently, ${ }^{137}$ we have been able to 


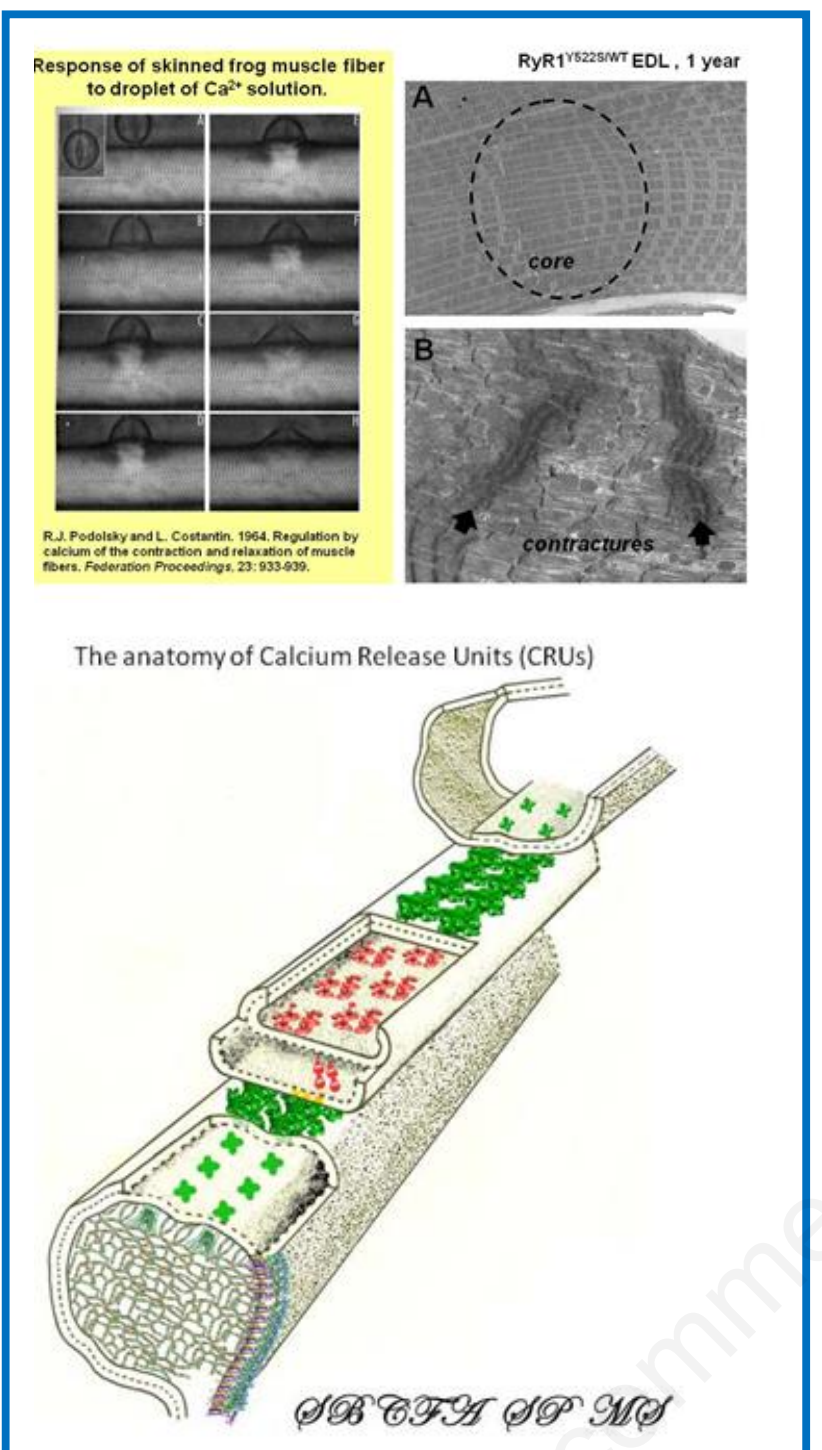

Fig 22. What images tell if you look closely

demonstrate that the main morphological alteration in a mouse model of Central Core Disease is the presence of contracture regions that eventualy evolve into cores lacking mitochondria. The evidence was based on accurately determining the actual frequency of supercontracted areas within different samples. These regions where similar to those described several years ago by Podolsky and Costantin in which they studied the response in a small portion of a skinned fiber to a droplet of Calcium solution (Figure 22, upper panels). ${ }^{138}$ In the $2012,{ }^{139}$ we published a paper illustrating how the contributions of Triadin and Junctin in the organization of Calsequestrin within the junctional sarcoplasmic reticulum (jSR) were simply deduced by a nanoscale description of the triad ultrastructure in the presence and absence of triadin/junction (Figure 22, lower panel). E.M. has been able to reveal a possibile contribution of Triadin and Junctin in the organization of Calsequestrin within the junctional sarcoplasmic reticulum (jSR) and on jSR architecture of skeletal muscle.
136. Huxley AF and Niedergerke R. Structural changes in muscle during contraction; interference microscopy of living muscle fibres. Nature 1954;173(4412):971-3.

137. Boncompagni $S$, Rossi AE, Micaroni $M$, et al. Characterization and temporal development of cores in a mouse model of malignant hyperthermia. Proc Natl Acad Sci U S A 2009;106:21996-2001.

138. Podolsky RJ, Costantin LL. Regulation by Calcium of the Contraction and Relaxation of Muscle Fibers. Fed Proc 1964;23:933-9.

139. Boncompagni S, Thomas M, Lopez JR, et al. Triadin/Junctin double null mouse reveals a differential role for Triadin and Junctin in anchoring CASQ to the $j S R$ and regulating $\mathrm{Ca}(2+)$ homeostasis. PLoS One 2012;7:e39962.

$$
* * * * *
$$

\section{Assessment, monitoring, prediction and decision making: different applications from multimodal muscle analysis}

Paolo Gargiulo (a,b), Kyle J. Edmunds (a), Magnús K. Gíslason (a),Ugo Carraro (c-e) , Halldór jr Jónsson (f)

(a) Institute for Biomedical and Neural Engineering, Reykjavík University, Reykjavík, Iceland; (b)

Department of science, Landspitali, Reykjavík, Iceland;(c) IRRCS Fondazione Ospedale San Camillo, Venezia, Italy; (d) A\&C M-C Foundation for

Translational Myology, Padova, Italy;(e) CIR-Myo Myology Center, University of Padova, Italy; (f)Faculty of Medicine, University of Iceland, Reykjavík, Iceland

\section{E-mail: paologar@landspitali.is}

Kaywords: medical imaging, numerical profile, muscle assessment, bone density

This work will show the development and the utility of patient specific muscles and bone assessment from single and multimodal measurements. The work presented outline methods and applications of threshold-based techniques, gait analysis and EMG to assess in vivo muscle and bone tissue distribution in normal and pathological conditions using computed tomography (CT) imaging and movement analysis technologies. These technologies and techniques are used to study bone mechanical proprieties, analyze and quantify muscle morphology, visualize changes with 3D models, develop subject specific numerical profiles, and assess muscle and bone changes during clinical treatments (Figure 23). Applications of these methodologies are employed: to simulate bone mechanics under particular stressful situation, to depict subject specific muscle profiling associated with age and pathology, to illustrate and quantify muscle degeneration and its partial reversal via Functional Electrical Stimulation (FES), ${ }^{140-144}$ and to highlight recovery following total hip arthroplasty (THA). ${ }^{145}$ 
a

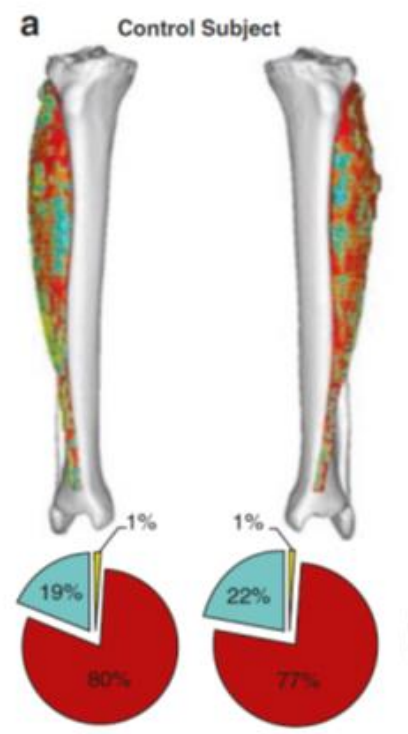

b Elderly Subject

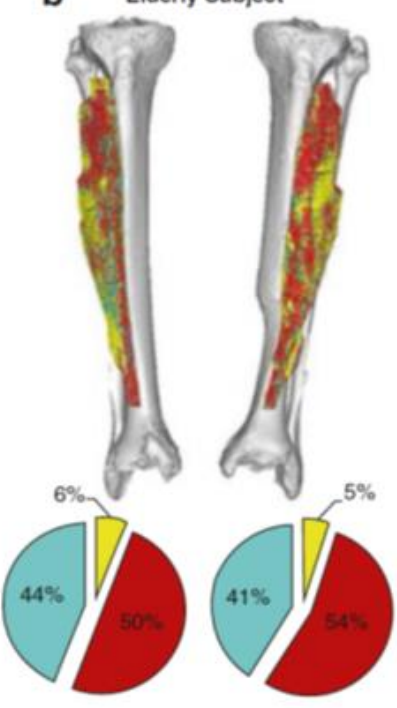

C Pathological Subject

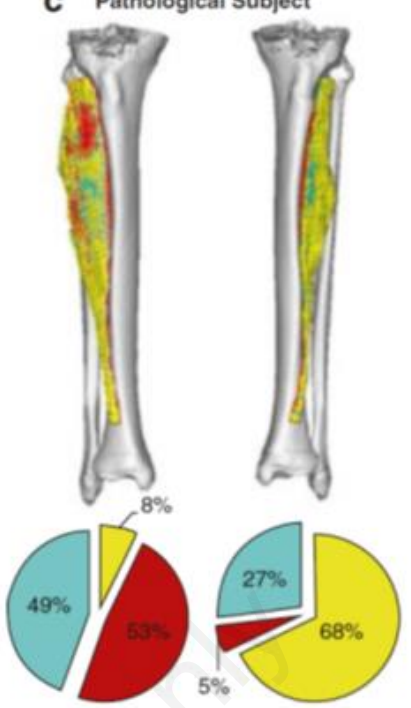

Fig 23. Segmented soft tissues and compositions within the Tibialis anterioris from each subject's $3 D$ upper leg volumes. Tissue types are as follows: fat (yellow), connective tissue (cyan), and muscle (red). a, The control subject's composition is primarily muscle, but b, the elderly subject had markedly more fat and connective tissue, to the detriment of muscle. c, However, the pathological subject's healthy leg composition was analogous to those of the elderly subject, but the pathological leg comprised of nearly all fat and connective tissue. ${ }^{133}$

140. Power GA, Dalton BH, Gilmore KJ, et al. Maintaining Motor Units into Old Age: Running the Final Common Pathway. Eur J Transl Myol 2017;27:6597. doi: 10.4081/ejtm.2017.6597. eCollection 2017 Feb 24.

141. Kern H, Carraro U. Home-Based Functional Electrical Stimulation for Long-Term Denervated Human Muscle: History, Basics, Results and Perspectives of the Vienna Rehabilitation Strategy. Eur J Transl Myol 2014;24(1):3296. doi: 10.4081/ejtm.2014.3296. eCollection 2014 Mar 31.

142. Gargiulo P, Edmunds KJ, Arnadottir ID, et al. Muscle Assessment Using 3D Modeling and Soft Tissue CT Profiling. In: Masiero S., Carraro U. (eds) Rehabilitation Medicine for Elderly Patients. Practical Issues in Geriatrics. Springer, Cham 2018; pp 213-221. https://doi.org/10.1007/978-3319-57406-6_24.

143. Ortolan P, Zanato $R$, Coran A, et al. Role of Radiologic Imaging in Genetic and Acquired Neuromuscular Disorders. Eur J Transl Myol 2015;25(2):5014. doi: 10.4081/ejtm.2015.5014. eCollection 2015 Mar 11. Review.

144. Sajer S. Mobility disorders and pain, interrelations that need new research concepts and advanced clinical commitments. Eur J Transl Myol. 2017 Dec 5;27(4):7179. doi: 10.4081/ejtm.2017.7179. eCollection 2017 Dec 5.
145. Magnússon B, Pétursson $P$, Edmunds $K$, et al. Improving Planning and Post-Operative Assessment for Total Hip Arthroplasty. Eur J Transl Myol. 2015 Mar 11;25(2):4913. doi: 10.4081/ejtm.2015.4913. eCollection 2015 Mar 11.

$$
* * * * *
$$

Automated segmentation and morphometric analysis of muscle fibers from H\&E stained histological sections

Claus Gerstenberger (a), Michael Karbiener (a), Nikolaus Jaufer (b), Thomas Pock (b), Martin Urschler (c), Markus Gugatschka (a)

(a) Department of Phoniatrics, ENT University Hospital, Medical University of Graz, Graz, Austria. (b) Institute for Computer Graphics and Vision, Graz

University of Technology, Graz, Austria. (c) Ludwig Boltzmann Institute for Clinical Forensic Imaging, Graz University of Technology, Graz, Austria

E-mail: claus.gerstenberger@medunigraz.at

Key words: Automated segmentation, morphometry of muscle fibers, haematoxylin-eosin-stained histological sections 


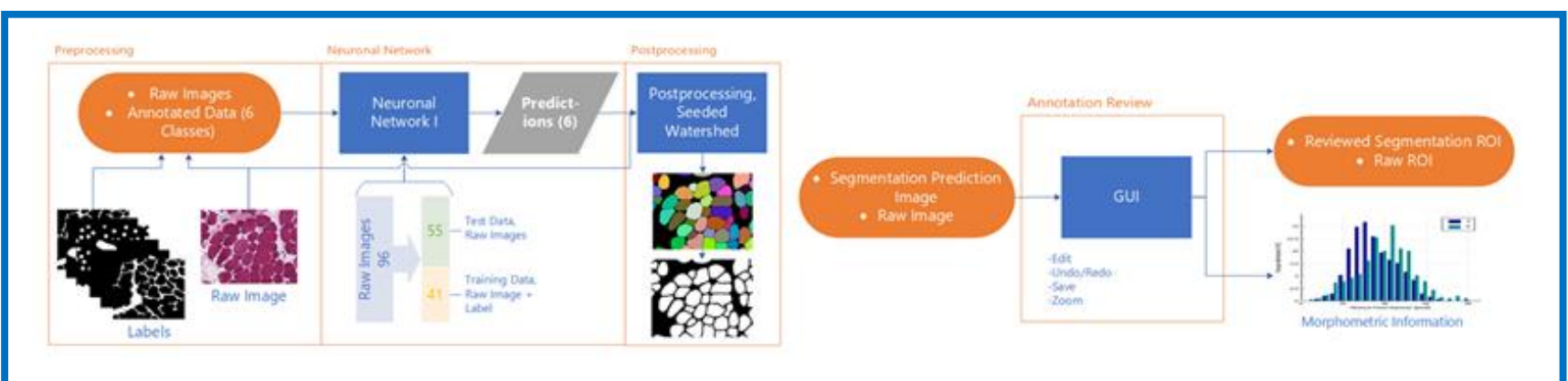

Fig 24. Neural network pipeline: From raw image to histogram display of morphometric data with graphical user interface (GUI) for manual refinement of automated segmentation to train the neural network.

We aim to introduce a new tool to ease the analysis and quantification of muscle specific parameters from histological sections by automatically segmenting digitized haematoxylin-eosin (H\&E) stained slides. H\&E staining is a standardized and cheap procedure in most laboratories worldwide. In contrast to existing time consuming, cost- and labour-intensive methods e.g. multiple immunofluorescence labelling, ${ }^{146}$ this new approach could accelerate the analysis and evaluation of histological sections by providing an automated calculation of morphometric information. Evaluating the effects of FES (functional electrical stimulation) in aged muscles is a possible application. ${ }^{147}$ Standard H\&E stained sections were digitized and loaded onto our new analysis software tool programmed by our partners from the Graz University of Technology, which automatically extracts morphometric information about the size of cells in a rapid and accurate way. For this purpose, the images were fully automatically normalized depending on their intensities and segmented to identify individual muscle cells and their margins. In a postprocessing step quantitative statistical information, as well as a histogram display are created (Figure 24). Machine-learning algorithms (Deep Neural Networks) have been implemented, as they proved to be very powerful methods for automatic image segmentation, especially in the field of histological analyses. ${ }^{148}$ A simple user interface was created to manage image data handling and to refine the segmentation manually, which enables an expert to train the neural network and thus to improve the automated results. As a result of developing this new software, specific outcome parameters can be obtained quickly and efficiently and are comparable to those obtained with the more time consuming and costintensive method of immunofluorescence labelling. Artefacts on the digitized H\&E slides originating from freezing, cutting or staining are automatically suppressed. ${ }^{149,150}$ However, muscle fiber types cannot be distinguished by using this method. Our automated segmentation approach is a promising new way to efficiently assess cell specific parameters based on H\&E stained slides with full potential to be extended to other light and electron microscopy muscle imaging approaches.
146. Tulloch L, Perkins J, Piercy $R$. Multiple immunofluorescence labelling enables simultaneous identification of all mature fibre types in a single equine skeletal muscle cryosection. Equine veterinary journal 2011;43:500-3.

147. Karbiener M, Jarvis JC, Perkins JD, et al. Reversing Age Related Changes of the Laryngeal Muscles by Chronic Electrostimulation of the Recurrent Laryngeal Nerve. PLoS One 2016;11: e0167367.

148. Cireşan DC, Giusti A, Gambardella LM, Schmidhuber J, et al. Mitosis detection in breast cancer histology images with deep neural networks. Med Image Comput Comput Assist Interv 2013;16:411-8.

149. Chatterjee S. Artefacts in histopathology. J Oral Maxillofac Pathol. 2014;18(Suppl 1):S111-S116. doi: 10.4103/0973-029X.141346.

150. Meng H, Janssen PML, Grange RW, et al. Tissue triage and freezing for models of skeletal muscle disease. Journal of visualized experiments: JoVE. 2014;89:51586. doi: $10.3791 / 5586$.

$$
* * * * *
$$

What FES rehabilitation of denervated muscles does and does not: Clinical Imaging Evidence

\section{Ugo Carraro (1,2), Helmut Kern (3), Paolo Gargiulo} (4), Amber Pond (5)

(1) CIR-Myo, University of Padova, Italy; (2) A\&CM-C Foundation for Translational Myology, Padova, Italy;

(3) Physiko- und Rheumatherapie, St. Poelten, Austria;

(4) Institute for Biomedical and Neural Engineering and Biomedical Technology Centre Reykjavik University \& Landspitali, Iceland; (5)Anatomy Department, Southern Illinois University School of Medicine, Carbondale, IL, USA

\section{E-mail:ugo.carraro@unipd.it}

Key words: FES rehabilitation, denervated muscles, Quantitative Muscle Color Computed Tomography (QMC-CT)

Skeletal muscle atrophy is the loss of muscle bulk and strength that occurs with neural and skeletal muscle injuries, prolonged bed rest, space flight, normal aging, and cachectic diseases such as cancer, sepsis, diabetes, nephropaties, etc. If unabated, skeletal muscle atrophy can be extremely debilitating, increasing morbidity and 

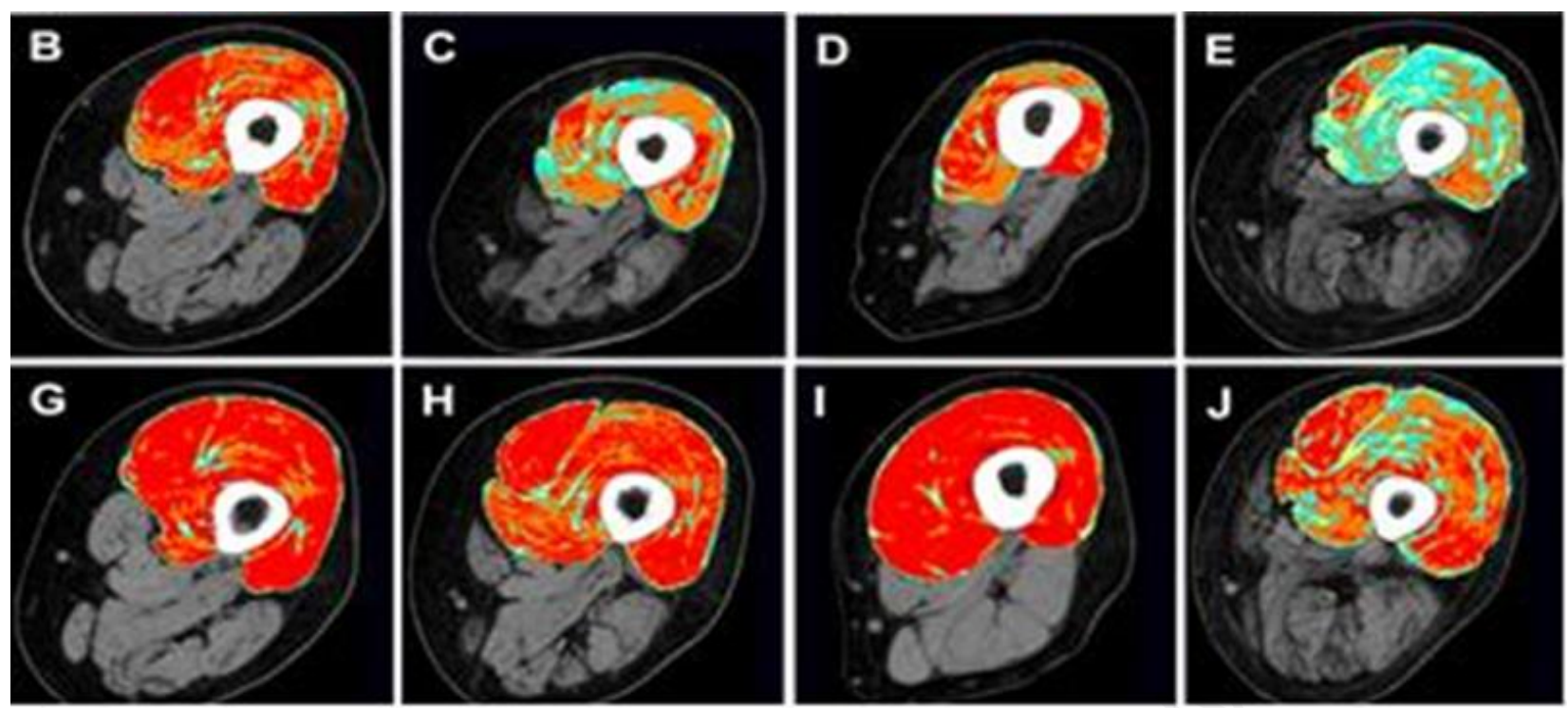

Fig 25. H-bFES of permanent denervated muscles in complete Conus and Cauda Syndrom, a particularly severe SCI. Two years of training reverse pacompletely or partially muscle atrophy/degeneration. Compare panels $B-E$ with G-J, that are Muscle Color Computed Tomography imaging of the same leg before and after two year of training. Notice that also the Hamstrings muscles recoverwhen the Quadriceps muscle was stimulated by large surface electrodes.

mortality in affected people. Current strategies by clinical imaging for diagnosis and evaluation of skeletal muscle are not adequate to evaluate quantitatively these conditions. Thus, proper diagnosis and treatment are often delayed, resulting in unnecessary human discomfort and down time. Quantitative Muscle Color Computed Tomography (QMC-CT) is a highly sensitive quantitative imaging analysis of one muscle or groups of anatomically defined skeletal muscles introduced by our group to monitor skeletal muscle tissue. ${ }^{151,152}$ Despite its powerful potential, this technique is not widely recognized. Therefore, one of our aims is to validate QMC-CT as a superior Muscle Imaging technique to quantitate skeletal muscle atrophy, degeneration and dystrophy, extending its acceptance from continental Europe to the rest of the world, in the first instance to U.S. Army and Veterans Hospitals. Validation of QMCCT will provide physicians an improved tool to quantitate skeletal muscle before and during rehabilitation strategies so that therapy for mobility-impaired persons can be better prescribed, evaluated and altered where needed. A recent report from the U.S. Army describes injuries as an "epidemic" which has become the "number one health threat" to the U.S. military. It has been reported that non-combat injuries have resulted in more medical air evacuations from Iraq and Afghanistan than combat injuries. ${ }^{153}$ These injuries result in physical discomfort and potential mental duress in addition to some degree of personnel down time. The more serious injuries can result in life long issues, as is the case of Spinal Cord Injuries (SCI). Of particular importance in SCI is whether the connection between the muscle and the nerve is preserved or the muscle is denervated due to complete peripheral nerve lesion. In the latter cases the denervated muscle becomes unexcitable with commercial electrical stimulators and undergoes ultra structural disorganization within a few months, while severe atrophy with nuclear clumping and fibro-fatty degeneration appears later on within 3 and 6 years. ${ }^{151,152,154-156}$ QMC-CT will provide medical personnel with a superior technique for imaging skeletal muscle and surrounding tissues, enhancing speed and accuracy of patient evaluation, thus improving diagnosis, treatment and patient morale. We here present the case of the conus and cauda equina complete syndrome and the results of maintained or discontinued Functional Electrical Stimulation of the denervated thigh muscles that may be observed using QMC-CT (Figure 25). In the long term, the improved treatments will reduce patient training time, personnel down time and enduring negative injury-related issues. Because the imaging technology could be used in both military and nonmilitary facilities, the method has the potential to improve health care for soldiers, veterans and the population at large.

151. Kern H, Carraro U, Adami N, et al. Home-based Functional Electrical Stimulation (h-b FES) recovers permanently denervated muscles in paraplegic patients with complete lower motor neuron lesion. Neurorehab Neur Rep 2010;24:709-21.

152. Edmunds KJ, Gíslason MK, Arnadottir ID, et al. Quantitative Computed Tomography and Image Analysis for Advanced Muscle Assessment. Eur J Transl Myol 2016;26:6015. doi: 10.4081/ejtm.2016.6015. 


\section{SpPMD: Giovanni Salviati Memorial, March 15-17}

Eur J Transl Myol 28 (1): 30-48, 2018

153. Hauschild V. Injury Prevention Program, U.S. Army Public Health Command. 2015. Non-battle injuries result in more medical evacuations than combat. https://www.army.mil/article/141818/.

154. Carraro U, Kern H, Gava P, et al. Recovery from muscle weakness by exercise and FES: lessons from Masters, active or sedentary seniors and SCI patients. Aging Clin Exp Res 2017;29:579-90. doi: 10.1007/s40520-0160619-1. Epub 2016 Sep 3. Review..

155. Zampieri S, Mosole S, Löfler S, et al. Physical Exercise in Aging: Nine Weeks of Leg Press or Electrical Stimulation Training in 70 Years Old Sedentary Elderly People. Eur J Transl Myol 2015; 25: 237-42. doi: 10.4081/ejtm. 2015.5374.

156. Carraro U, Gava K, Baba A, et al. Fighting muscle weakness in advanced aging by take-home strategies: Safe anti-aging full-body in-bed gym and functional electrical stimulation (FES) for mobility compromised elderly people. Biol Eng Me 2016;1:1-4. doi: 10.15761/ BEM.1000106.

$$
* * * * *
$$

\section{Cumulative references of Chapter III}

85. Sabbadini R, McNutt W, Jenkins G, Betto R, Salviati G. Sphingosine is endogenous to cardiac and skeletal muscle. Biochem Biophys Res Commun. 1993;193:752-8.

86. Betto R, Teresi A, Turcato F, Salviati G, Sabbadini RA, Krown K, Glembotski CC, Kindman LA, Dettbarn C, Pereon $Y, \quad Y a s u i \quad K, \quad$ Palade PT. Sphingosylphosphocholine modulates the ryanodine receptor/calcium-release channel of cardiac sarcoplasmic reticulum membranes. Biochem J 1997;322 ( Pt 1):327-33.

87. Dettbarn CA, Betto R, Salviati G, Palade P, Jenkins GM, Sabbadini RA. Modulation of cardiac sarcoplasmic reticulum ryanodine receptor by sphingosine. J Mol Cell Cardiol 1994;26:229-42.

88. Reynolds GM, Visentin B, Sabbadini $R$. Immunohistochemical Detection of Sphingosine-1Phosphate and Sphingosine Kinase-1 in Human Tissue Samples and Cell Lines. Methods Mol Biol 2018;1697:43-56. doi: 10.1007/7651_2017_44.

89. Tsuji S, Chen X, Hancock B, et al. Preclinical evaluation of VAX-IP, a novel bacterial minicell-based biopharmaceutical for nonmuscle invasive bladder cancer. Mol Ther Oncolytics 2016;3:16004. doi: 10.1038/mto.2016.4. eCollection 2016.

90. Bouquerel P, Gstalder C, Müller D, et al. Essential role for SphK1/S1P signaling to regulate hypoxia-inducible factor $2 \alpha$ expression and activity in cancer. Oncogenesis. 2016;5:e209. doi: 10.1038/oncsis.2016.13.

91. Larsson L, Li X, Edström L, Eriksson LI, et al. Loss of muscle myosin and acute quadriplegia in patients treated with non-depolarizing neuromuscular blocking agents and corticosteroids. Underlying cellular and molecular mechanisms. Critical Care Medicine 2000;28:34-45.

92. Ochala J, Gustafson A-M, Li M, et al. Preferential skeletal muscle myosin loss in response to mechanical silencing in a novel rat intensive care unit model: underlying mechanisms. $J$ Physiol (Lond) 2011;589:2007-26.

93. Renaud G, Llano-Diez, M, Ravara B, et al. . Sparing of muscle mass and function by passive loading in an experimental intensive care unit model $J$ Physiol 2013;591(Pt 5):1385-402.

94. Llano-Diez M, Renaud $G$, Andersson M, et al. Passive mechanical loading improves muscle function but not mass in immobilized intensive care unit patients. Critical Care 2012;16:R209 doi:10.1186/cc11841

95. Corpeno R, Dworkin B, Bergman H-M, et al. Time-course analysis of mechanical ventilation-induced diaphragm contractile muscle dysfunction. J Physiol 2014:592:3859-80.

96. Salah H, Li M, Cacciani N, Gastaldello S,et al. The chaperone co-inducer BGP-15 alleviates ventilation induced diaphragm dysfunction Science Translational Medicine 2016;8(350):350ra103. doi: 10.1126/scitransl med.aaf7099.

97. Hoffman EP, Brown RH Jr, Kunkel LM. Dystrophin: the protein product of the Duchenne muscular dystrophy locus. Cell 1987 Dec 24;51(6):919-28.

98. Bonilla E, Samitt CE, Miranda AF, et al. Duchenne muscular dystrophy: deficiency of dystrophin at the muscle cell surface. Cell 1988;54:447-52.

99. Salviati $G$, Betto $R$, Ceoldo $S$, et al. Cell fractionation studies indicate that dystrophin is a protein of surface membranes of skeletal muscle. Biochem J 1989;258:83741.

100. Luise M, Presotto C, Senter L, et al. Dystrophin is phosphorylated by endogenous protein kinases. Biochem J 1993;293:243-7.

101. Senter L, Ceoldo S, Petrusa MM, Salviati G. Phosphorylation of dystrophin: effects on actin binding. Biochem Biophys Res Commun 1995;206:57-63.

102. Betto R, Senter L, Ceoldo S, et al. Ecto-ATPase activity of alpha-sarcoglycan (adhalin). $J$ Biol Chem 1999;274:7907-12.

103. Sandonà D, Betto R. Sarcoglycanopathies: molecular pathogenesis and therapeutic prospects. Expert Rev Mol Med 2009; 11:e28.

104. Gastaldello S, D'Angelo S, Franzoso S, et al. Inhibition of proteasome activity promotes the correct localization of disease-causing $\alpha$-sarcoglycan mutants in HEK-293 cells constitutively expressing $\beta$-, $\gamma$-, and $\delta$-sarcoglycan. Am J Pathol 2008; 173:170-81.

105. Bianchini E, Fanin M, Mamchaoui K, et al. Unveiling the degradative route of the V247M $\alpha$-sarcoglycan mutant responsible for LGMD-2D. Hum Mol Genet 2014;23:3746-58.

106. Carotti M, Marsolier J, Soardi M, et al. Repairing folding-defective $\alpha$-sarcoglycan mutants by CFTR correctors, a potential therapy for Limb Girdle Muscular Dystrophy 2D. Hum Mol Genet 2018, in press.

107. Yun J, Finkel T. Mitohormesis. Cell Metab 2014;19:75766. 


\section{SpPMD: Giovanni Salviati Memorial, March 15-17}

Eur J Transl Myol 28 (1): 30-48, 2018

108. Brand M. Mitochondrial generation of superoxide and hydrogen peroxide as the source of mitochondrial redox signaling. In Free Radic Biol Med 2016, pp. 14-31.

109. El-Khoury R., Kemppainen K., Dufour, et al. Engineering the alternative oxidase gene to better understand and counteract mitochondrial defects: state of the art and perspectives. Br J Pharmacol 2014;171:2243-9.

110. Wrogemann K, Pena SD. Mitochondrial calcium overload: A general mechanism for cell-necrosis in muscle diseases. Lancet 1976;1:672-4.

111. Zulian A, Schiavone M, Giorgio V, Bernardi P. Forty years later: Mitochondria as therapeutic targets in muscle diseases. Pharmacol Res 2016;113:563-73.

112. Tiepolo T, Angelin A, Palma E, et al. The cyclophilin inhibitor Debio 025 normalizes mitochondrial function, muscle apoptosis and ultrastructural defects in Col6a1 -/ myopathic mice. Br J Pharmacol 2009;157:1045-52.

113. Millay DP, Sargent MA, Osinska H, et al. Genetic and pharmacologic inhibition of mitochondrial-dependent necrosis attenuates muscular dystrophy. Nat Med 2008; 14:442-7.

114. Schiavone M, Zulian A, Menazza S, et al. Alisporivir rescues defective mitochondrial respiration in Duchenne muscular dystrophy. Pharmacol Res 2017;125:122-31.

115. Wissing ER, Millay DP, Vuagniaux G, Molkentin JD. Debio-025 is more effective than prednisone in reducing muscular pathology in mdx mice. Neuromuscul Disord 2010;20:753-60.

116. Vazquez Fonseca L, Doimo M, Calderan $C$, et al. Mutations in COQ8B (ADCK4) found in patients with steroid-resistant nephrotic syndrome alter COQ8B function. Hum Mutat 2018;39:406-414. doi: 10.1002/hити.23376. Ерub 2017 Dec 18.

117. Salviati L, Trevisson E1, Doimo M, Navas P. Primary Coenzyme Q10 Deficiency. Editors. In: Adam MP, Ardinger HH, Pagon RA, Wallace SE, Bean LJH, Stephens K, Amemiya A, editors. Source, GeneReviews ${ }^{\circledR}$ [Internet]. Seattle (WA): University of Washington, Seattle; 1993-2018. 2017 Jan 26.

118. Biral D, Betto R, Danieli-Betto D, Salviati G. Myosin heavy chain composition of single fibres from normal human muscle. Biochem J 1988;250:307-8.

119. Klitgaard H, Zhou M, Schiaffino S, et al. Ageing alters the myosin heavy chain composition of single fibres from human skeletal muscle. Acta Physiol Scand. 1990;140:55-62.

120. Bottinelli R, Schiaffino S, Reggiani C. Force-velocity relations and myosin heavy chain isoform compositions of skinned fibres from rat skeletal muscle. J Physiol 1991;437:655-72.

121. Murgia M, Nagaraj N, Deshmukh AS, et al. Single muscle fiber proteomics reveals unexpected mitochondrial specialization. EMBO Rep 2015;16:387-95.

122. Schiaffino S, Reggiani $C$, Kostrominova $T Y$, et al. Mitochondrial specialization revealed by single muscle fiber proteomics: focus on the Krebs cycle. Scand J Med Sci Sports. 2015;25(Suppl 4):41-8.

123. Murgia M, Toniolo L, Nagaraj N, et al. Single muscle fiber proteomics reveals fiber-type-specific features of human muscle aging. Cell Rep 2017;19:2396-409.

124. Judson RN, Tremblay AM, Knopp, P, et al. The Hippo pathway member Yap plays a key role in influencing fate decisions in muscle satellite cells. $J$ cell sci 2012:125:6009-19.

125. Tremblay AM, Missiaglia E, Galli GG, et al. The Hippo transducer YAP1 transforms activated satellite cells and is a potent effector of embryonal rhabdomyosarcoma formation. Cancer cell 2014;26,273-87 87. doi: 10.1016/j.ccr.2014.05.029. Epub 2014 Jul 31.

126. Judson RN, Gray SR, Walker C, et al. Constitutive expression of Yes-associated protein (Yap) in adult skeletal muscle fibres induces muscle atrophy and myopathy. PloS one 2013;8:e59622.

127. des Georges A., Clarke O.B., Zalk R., et al. Structural basis for gating and activation of RyRl. Cell 2016;167:145-57.

128. Rousseau E, Ladine J, Liu QY, Meissner G. Activation of the $\mathrm{Ca}+$ release channel of skeletal muscle sarcoplasmic reticulum by caffeine and related compounds. Arch. Biochem. Biophys 1988.267:75-86.

129. Salviati $G$, Volpe P. Ca2+ release from sarcoplasmic reticulum of skinned fast- and slow-twitch muscle fibers. Am J Physiol 1988:254:C459-465

130. Lamb GD, Cellini MA, Stephenson DG. Different Ca2+ releasing action of caffeine and depolarisation in skeletal muscle fibres of the rat. J Physiol 2001;531:715-28.

131. Makabe M, Werner O, Fink RH. The contribution of the sarcoplasmic reticulum Ca2+-transport ATPase to caffeine-induced Ca2+ transients of murine skinned skeletal muscle fibres. Pflugers Arch 1996;432:717-26.

132. Uttenweiler D, Weber C, Fink RH. Mathematical modeling and fluorescence imaging to study the Ca2+ turnover in skinned muscle fibers. Biophys $J$ 1998;74:1640-53

133. Rossi R, Bottinelli R, Sorrentino V, Reggiani C. Response to caffeine and ryanodine receptor isoforms in mouse skeletal muscles. Am J Physiol Cell Physiol. 2001;281:C585-94.

134. Rossi D, Vezzani B, Galli L, et al. A Mutation in the CASQ1 Gene Causes a Vacuolar Myopathy with Accumulation of Sarcoplasmic Reticulum Protein Aggregates. Hum Mutat 2014;35:1163-70.

135. Barone V, Del Re V, Gamberucci A, et al. Identification and characterization of three novel mutations in the CASQ1 gene in four patients with tubular aggregate myopathy. Hum Mutat. 2017 ;38:1761-73.

136. Huxley $A F$ and Niedergerke R. Structural changes in muscle during contraction; interference microscopy of living muscle fibres. Nature 1954;173(4412):971-3.

137. Boncompagni $S$, Rossi AE, Micaroni $M$, et al. Characterization and temporal development of cores in a 


\section{SpPMD: Giovanni Salviati Memorial, March 15-17}

Eur J Transl Myol 28 (1): 30-48, 2018

mouse model of malignant hyperthermia. Proc Natl Acad Sci U S A 2009; 106:21996-2001.

138. Podolsky RJ, Costantin LL. Regulation by Calcium of the Contraction and Relaxation of Muscle Fibers. Fed Proc 1964;23:933-9.

139. Boncompagni $S$, Thomas $M$, Lopez JR, et al. Triadin/Junctin double null mouse reveals a differential role for Triadin and Junctin in anchoring CASQ to the jSR and regulating $\mathrm{Ca}(2+)$ homeostasis. PLoS One 2012;7:e39962.

140. Power GA, Dalton BH, Gilmore KJ, et al. Maintaining Motor Units into Old Age: Running the Final Common Pathway. Eur J Transl Myol 2017;27:6597. doi: 10.4081/ejtm.2017.6597. eCollection 2017 Feb 24.

141. Kern H, Carraro U. Home-Based Functional Electrical Stimulation for Long-Term Denervated Human Muscle: History, Basics, Results and Perspectives of the Vienna Rehabilitation Strategy. Eur J Transl Myol 2014;24(1):3296. doi: 10.4081/ejtm.2014.3296. eCollection 2014 Mar 31.

142. Gargiulo P, Edmunds KJ, Arnadottir ID, et al. Muscle Assessment Using 3D Modeling and Soft Tissue CT Profiling. In: Masiero S., Carraro U. (eds) Rehabilitation Medicine for Elderly Patients. Practical Issues in Geriatrics. Springer, Cham 2018; pp 213-221. https://doi.org/10.1007/978-3-319-57406-6_24.

143. Ortolan P, Zanato R, Coran A, et al. Role of Radiologic Imaging in Genetic and Acquired Neuromuscular Disorders. Eur J Transl Myol 2015;25(2):5014. doi: 10.4081/ejtm.2015.5014. eCollection 2015 Mar 11. Review.

144. Sajer S. Mobility disorders and pain, interrelations that need new research concepts and advanced clinical commitments. Eur J Transl Myol. 2017 Dec 5;27(4):7179. doi: 10.4081/ejtm.2017.7179. eCollection 2017 Dec 5.

145. Magnússon B, Pétursson P, Edmunds K, et al. Improving Planning and Post-Operative Assessment for Total Hip Arthroplasty. Eur J Transl Myol. 2015 Mar 11;25(2):4913. doi: $10.4081 /$ ejtm.2015.4913. eCollection 2015 Mar 11.

146. Tulloch L, Perkins J, Piercy $R$. Multiple immunofluorescence labelling enables simultaneous identification of all mature fibre types in a single equine skeletal muscle cryosection. Equine veterinary journal 2011;43:500-3.
147. Karbiener M, Jarvis JC, Perkins JD, et al. Reversing Age Related Changes of the Laryngeal Muscles by Chronic Electrostimulation of the Recurrent Laryngeal Nerve. PLoS One 2016;11: e0167367.

148. Cireşan DC, Giusti A, Gambardella LM, Schmidhuber J, et al. Mitosis detection in breast cancer histology images with deep neural networks. Med Image Comput Comput Assist Interv 2013;16:411-8.

149. Chatterjee S. Artefacts in histopathology. J Oral Maxillofac Pathol. 2014;18(Suppl 1):S111-S116. doi: 10.4103/0973-029X.141346.

150. Meng H, Janssen PML, Grange RW, et al. Tissue triage and freezing for models of skeletal muscle disease. Journal of visualized experiments: JoVE. 2014;89:51586. doi: 10.3791/5586.

151. Kern H, Carraro U, Adami $N$, et al. Home-based Functional Electrical Stimulation (h-b FES) recovers permanently denervated muscles in paraplegic patients with complete lower motor neuron lesion. Neurorehab Neur Rep 2010;24:709-21.

152. Edmunds KJ, Gíslason MK, Arnadottir ID, et al. Quantitative Computed Tomography and Image Analysis for Advanced Muscle Assessment. Eur J Transl Myol 2016;26:6015. doi: 10.4081/ejtm.2016.6015.

153. Hauschild V. Injury Prevention Program, U.S. Army Public Health Command. 2015. Non-battle injuries result in more medical evacuations than combat. https://www.army.mil/article/141818/.

154. Carraro U, Kern H, Gava P, et al. Recovery from muscle weakness by exercise and FES: lessons from Masters, active or sedentary seniors and SCI patients. Aging Clin Exp Res 2017;29:579-90. doi: 10.1007/s40520-0160619-1. Epub 2016 Sep 3. Review.

155. Zampieri S, Mosole S, Löfler S, et al. Physical Exercise in Aging: Nine Weeks of Leg Press or Electrical Stimulation Training in 70 Years Old Sedentary Elderly People. Eur J Transl Myol 2015; 25: 237-42. doi: 10.4081/ejtm. 2015.5374.

156. Carraro U, Gava K, Baba A, et al. Fighting muscle weakness in advanced aging by take-home strategies: Safe anti-aging full-body in-bed gym and functional electrical stimulation (FES) for mobility compromised elderly people. Biol Eng Me 2016;1:1-4. doi: 10.15761/ BEM.1000106.

Received for publication: February 20, 2018 Accepted for publication: February 21, 2018 